\title{
Whisker-Mediated Touch System in Rodents: From Neuron to Behavior
}

\author{
Mehdi Adibi ${ }^{1,2,3 *}$ \\ ${ }^{1}$ School of Psychology, University of New South Wales, Sydney, NSW, Australia, ${ }^{2}$ Tactile Perception and Learning Lab, \\ International School for Advanced Studies (SISSA), Trieste, Italy, ${ }^{3}$ Padua Neuroscience Center, University of Padua, Padua, \\ Italy
}

A key question in systems neuroscience is to identify how sensory stimuli are represented in neuronal activity, and how the activity of sensory neurons in turn is "read out" by downstream neurons and give rise to behavior. The choice of a proper model system to address these questions, is therefore a crucial step. Over the past decade, the increasingly powerful array of experimental approaches that has become available in non-primate models (e.g., optogenetics and two-photon imaging) has spurred a renewed interest for the use of rodent models in systems neuroscience research. Here, I introduce the rodent whisker-mediated touch system as a structurally well-established and well-organized model system which, despite its simplicity, gives rise to complex behaviors. This system serves as a behaviorally efficient model system; known as nocturnal animals, along with their olfaction, rodents rely on their whisker-mediated touch system to collect information about their surrounding environment. Moreover, this system represents a well-studied circuitry with a somatotopic organization. At every stage of processing, one can identify anatomical and functional topographic maps of whiskers;

OPEN ACCESS

Edited by: Ilan Lampl,

Weizmann Institute of Science, Israel

Reviewed by:

Vassiliy Tsytsarev,

University of Maryland, College Park,

United States

Sylvain Crochet,

École Polytechnique Fédérale de

Lausanne, Switzerland

Mickey London,

Hebrew University of Jerusalem, Israel

*Correspondence:

Mehdi Adibi

m.adibi@unsw.edu.au

Received: 22 August 2018 Accepted: 02 August 2019 Published: 21 August 2019

Citation: Adibi M (2019) Whisker-Mediated Touch System in Rodents: From Neuron to Behavior Front. Syst. Neurosci. 13:40. doi: 10.3389/fnsys.2019.00040 "barrelettes" in the brainstem nuclei, "barreloids" in the sensory thalamus, and "barrels" in the cortex. This article provides a brief review on the basic anatomy and function of the whisker system in rodents.

Keywords: rodents, whisker system, vibrissae, vibrissal system, somatosensory, barrel field, thalamic barreloids

\section{INTRODUCTION}

A fundamental goal of systems neuroscience is to identify how sensory stimuli are represented in neuronal activity, and how the activity of sensory neurons is "read out" by downstream neuronal structures to generate behavior. Researchers dissect this goal into the following questions:

1. What elemental features of sensory stimuli are encoded in the neuronal activity of sensory neurons?

2. How is each elemental feature represented in the activity of sensory neurons?

3. How do the downstream neuronal areas decode the activity of sensory neurons?

4. How does spatial and temporal context affect the efficiency with which single neurons and neuronal ensembles encode sensory stimuli?

5. How does the activity of neurons give rise to perception and ultimately behavior?

Over the past decade, the increasingly powerful array of experimental approaches such as optogenetics and two-photon imaging which has become available in non-primate models, particularly in rodents, has spurred a renewed interest for the use of rodents in neuroscience research. The aim of this article is to introduce the rodent whisker-mediated touch system as a model system suitable for investigating the fundamental questions in systems neuroscience. 
This model serves as an anatomically well-established and behaviorally efficient system; as nocturnal animals, rodents rely on their whisker-mediated touch system to collect information about their surrounding environment. Moreover, this system represents a well-studied circuitry with an elegant structural organization. At every stage of processing, one can identify anatomical and functional topographic maps of whiskers. These clusters are referred to as "barrelettes" in the brainstem nuclei, "barreloids" in the thalamus, and "barrels" in the cortex. Mapping studies have revealed that whisker-related areas occupy a relatively large proportion of neural tissue at trigeminal medullar level (28\%) (Nord, 1967), at the level of thalamic sensory nuclei (27\%) (Emmers, 1965), and at the cortical level (20\%) (Welker, 1971).

In the following sections, I first provide a brief introduction to the basic anatomy and then the function of the whisker system in rodents.

\section{THE WHISKER-MEDIATED TOUCH SYSTEM}

\subsection{Vibrissae and Follicles}

Rat vibrissae, or whiskers, form a grid-wise layout on either side of the snout. The main distinction of the vibrissae from ordinary hairs is their large follicles which contain dense nerve terminals and sensory receptors. As mechanical transducers, the vibrissae mediate the transfer of the touch signal into these receptors. The vibrissae are categorized into two classes: (i) the micro-vibrissae, which are short and thin hairs around the nose tip, and (ii) macro-vibrissae, which are the long stiff mystacial hairs caudal to micro-vibrissae on the whisker pad (Brecht et al., 1997). Macro-vibrissae consist of four follicles in rows A and B, seven to nine follicles in row $\mathrm{C}, \mathrm{D}$ and $\mathrm{E}$, and four straddlers $(\alpha, \beta, \gamma, \delta)$ straddling between rows caudal to the mystacial pad (see Figure 1).

These two classes of vibrissae are believed to be functionally distinct (Vincent, 1912; Brecht et al., 1997); the macrovibrissae transmit spatial information such as localization in space, as they sweep the environment by intrinsic muscles. However micro-vibrissae are considered to be involved in acquisition of detailed tactile information for object and texture recognition. Nevertheless, there is evidence from behavioral studies demonstrating that rodents are able to perform texture and vibration discrimination tasks using their macrovibrissae (Carvell and Simons, 1990; Krupa et al., 2001; von Heimendahl et al., 2007; Adibi and Arabzadeh, 2011; Morita et al., 2011; Adibi et al., 2012).

The nerve terminals and mechanoreceptors around the vibrissa shaft are of various types, morphologies and distributions (Melaragno and Montagna, 1953) including Merkel cell-neurite complexes, lanceolate receptors, Ruffini corpuscles-sometimes referred to as reticular endings-and free nerve endings (Renehan and Munger, 1986; Rice et al., 1986; Ebara et al., 2002). Different receptors show different tuning properties and sensitivity to a variety of tactile stimulus parameters such as amplitude, frequency, duration, velocity, acceleration and direction of whisker deflections/motion (Fitzgerald, 1940; Kerr and Lysak, 1964; Zucker and Welker, 1969; Hahn, 1971; Pubols et al., 1973; Dykes, 1975; Gibson and Welker, 1983a,b; Lichtenstein et al., 1990). These receptors also exhibit different profiles of adaptation. Merkel cells are the most prominent mechanoreceptors. These receptors adapt slowly to sustained whisker deflections, whereas lanceolate receptors and simple corpuscles are rapidly-adapting (Iggo and Muir, 1969; Zucker and Welker, 1969; Munger et al., 1971; Gottschaldt et al., 1973; Pubols et al., 1973; Dykes, 1975).

Each follicle is innervated by 150-200 myelinated and 100 unmyelinated distal axons of trigeminal ganglion neurons (Lee and Woolsey, 1975; Waite and Cragg, 1982; Renehan and Munger, 1986; Rice et al., 1986, 1997; Henderson and Jacquin, 1995). These axons arborize around the hair shaft, sensing movements in different directions.

\subsection{Whisking}

Whisking is the rhythmic cyclic vibrissae sweeping action, consisting of repetitive forward (protraction) and backward (retraction) movements at an average frequency of about $8 \mathrm{~Hz}$ (Welker, 1964; Wineski, 1983; Carvell et al., 1991). Whisking is often synchronous to respiratory, head, and nose movements, suggesting coordination of activity among many muscle groups (Welker, 1964; Cao et al., 2012). Berg and Kleinfeld (2003) observed two different patterns of whisking; the first pattern, referred to as the exploratory whisking, consists of wide-angle sweeps with a frequency range of 1 to $5 \mathrm{~Hz}$ in bouts of 1 to $10 \mathrm{~s}$. The whisking frequency within a bout remains remarkably constant, while it changes between bouts (Vincent, 1912; Welker, 1964; Wineski, 1983; Carvell and Simons, 1990; Carvell et al., 1991). The second pattern of whisking consists of small-amplitude high-frequency (ranging from 15 to $25 \mathrm{~Hz}$ ) sweeps for a period of 0.5 to $1 \mathrm{~s}$ while whiskers are thrust forward in a dense pattern (Carvell and Simons, 1990, 1995; Berg and Kleinfeld, 2003). This pattern resembles the dense focalized arrangement of photoreceptors in the retina fovea, and is therefore referred to as "foveal whisking". Movement of the follicle is controlled by the facial motor nerve. Macrovibrissae are moved by two sets of striated musculatures (Dörfl, 1982; Wineski, 1983, 1985); the intrinsic and extrinsic muscles. Intrinsic muscles lack a bony attachment and have their origin and insertions in the skin (Dörfl, 1982). They are associated with individual whiskers and generate the forward whisker motion (protraction) by pulling the base of the follicle backwards (Carvell et al., 1991). Extrinsic muscles are located superficially in the mystacial pad with no direct connection with follicles. They move all whiskers together (Wineski, 1983, 1985; Dörfl, 1985; Carvell et al., 1991). On the basis of anatomical observations, Dörfl $(1982,1985)$ and Wineski (1985) concluded that mystacial pad muscles move the whiskers forward (protraction), whereas backward motion (retraction) is mainly a result of the elastic properties of the facial tissue, and is therefore passive. A more recent finding, however, demonstrated that retraction is under the active muscular control as well (Berg and Kleinfeld, 2003).

Whisking is controlled by a neuronal oscillator located in the vibrissa-related region of intermediate reticular formation 


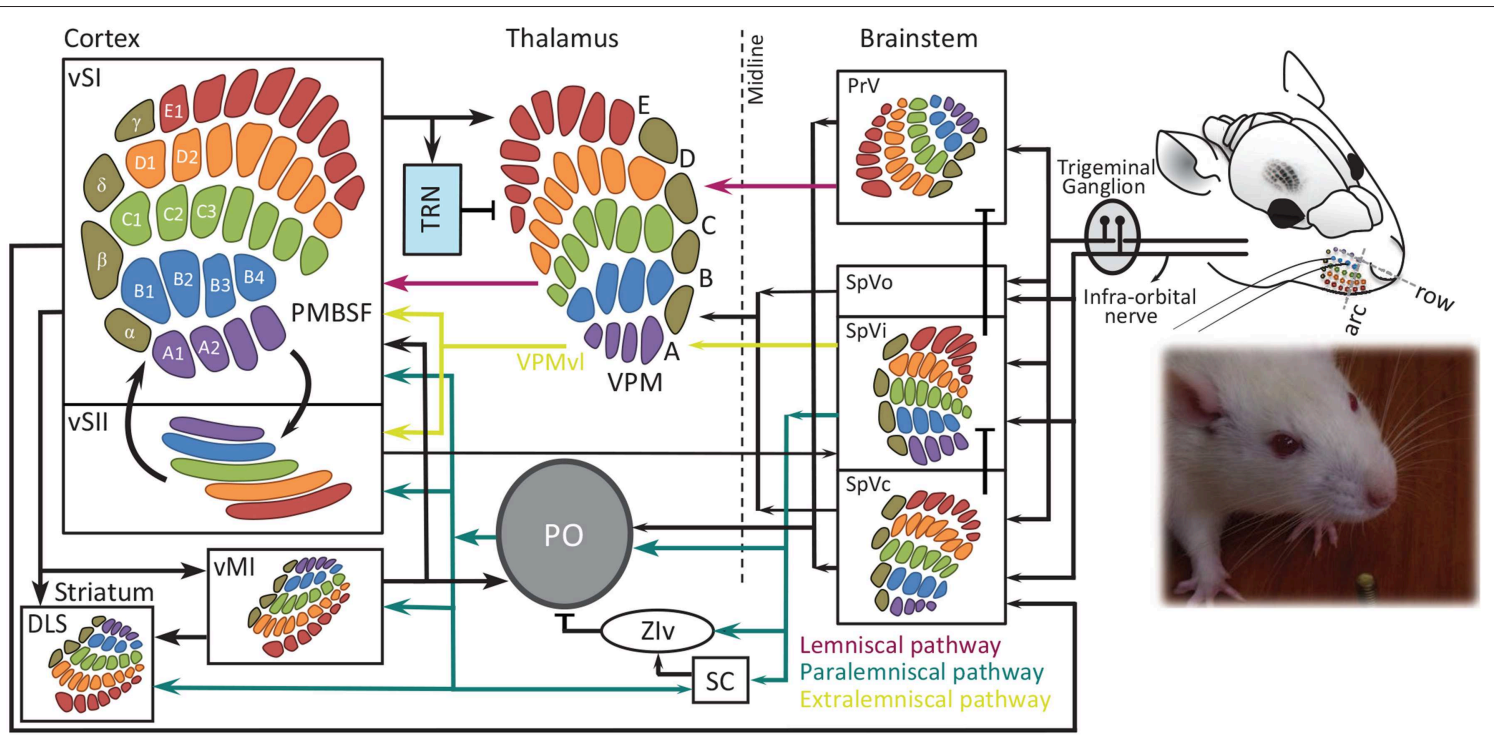

FIGURE 1 | Schematic representation of whisker-barrel system. Each whisker is identified by a unique letter-number combination corresponding to its row (A to $E$ from dorsal to ventral) and arc (identified by numbers 1, 2 and etcetera from caudal to rostral), with $\alpha, \beta, \gamma$, and $\delta$ straddlers between rows. Colors indicate rows. Barrel, barreloid and barrelets are redrawn from Durham and Woolsey (1984). PMBSF, posterior-medial barrel sub-field; PO, posterior thalamic nucleus; PrV, principal trigeminal nucleus; SC, superior colliculus; SpVi, spinal trigeminal nuclei pars interpolaris; SpVo, pars oralis; SpVc, pars caudalis; TRN, thalamic reticular nucleus; VPM, ventro-posterior medial nucleus; vMI, vibrissal primary motor cortex; vSI, vibrissal primary somatosensory cortex; vSII, secondary somatosensory cortex with the somatotopic map from Benison et al. (2007); DLS, dorsolateral striatum; Zlv, ventral zona inserta. The evidence for somatotopic map in vM1 is provided in Ferezou et al. (2007) and Sreenivasan et al. (2016)

of the medulla (vIRt) (Moore et al., 2013, 2014; Deschênes et al., 2016). This region includes facial premotor neurons and neurons that their spiking activity is either in phase or in antiphase with whisking protraction. Selective lesions in vIRt abolish whisking on the side of the lesion, and activation of the vIRt by iontophoretic injection of kainic acid (KA) induces long episodes of whisking under light ketamine anesthesia (Moore et al., 2014). Glycinergic/GABAergic neurons in vIRt rhythmically inhibit vibrissa facial motoneurons innervating the intrinsic muscles (Deschênes et al., 2016), suggesting that rhythmic whisking is driven by inhibition. During whisking, the intrinsic muscles protracting individual whiskers follow the whisking oscillation, while extrinsic muscles that move the mystacial pad follow the breathing rhythm. Both rhythms are phaselocked during sniffing (rapid rhythmic breathing) (Deschênes et al., 2012; Kleinfeld et al., 2014). This is compatible with the unidirectional connections from the pre-Bötzinger complexthe inspiratory oscillator for respiration located in medulla adjacent to IRt (Feldman and Kam, 2015) - to vIRt, revealing the contribution of pre-Bötzinger complex to the mystacial pad control by driving the extrinsic muscles together with the potential contribution of putative parafacial neurons that receive their input from pre-Bötzinger complex (Deschênes et al., 2016). There are no bilateral vIRt to vIRt connections. Thus, the bilateral synchronization of whisking is mediated by the medullary commissural fibers connecting the left and right preBötzinger complexes (Deschênes et al., 2016).

Whiskers on the right and left sides can move asymmetrically and asynchronously (Knutsen et al., 2006; Towal and Hartmann,
2008). Additionally, rostral and caudal whiskers on a single side of the snout can sometimes move independently. Recently, using a three-dimensional model of the vibrissal array, Huet and Hartmann (2014) quantified the search space during whisking and protraction. According to their calculations, the parabolic intrinsic curvature of the whiskers increases the volume of the search space by over $40 \%$ compared to that of the straight whiskers, while the elevation-whisker's angle relative to the horizontal plane-and torsion-torsional rotation of a whisker about its own axis-had modest effect on the search space. Elevation and torsion, however, affect the trajectory of the whisker tips. Dynamics of whisker movement reveal a rodent's expectations about the environment (Mitchinson et al., 2007; Grant et al., 2009). During locomotion, direction and speed of running are coupled with average whisker position (Towal and Hartmann, 2006, 2008; Mitchinson et al., 2011; Sofroniew et al., 2014). The fine-scale kinematics of the whisking motion in freely moving rodents, however, is difficult to characterize. Machine learning techniques such as deep learning (Hong et al., 2015), visually enhanced whiskers for tracking using florescent dyes (Rigosa et al., 2017) and precise controlled locomotion in virtual reality for head-fixed animal (Sofroniew et al., 2014) are promising future approaches for high precision characterization of whisker motion kinematics during locomotion.

\subsection{Trigeminal Ganglion}

Trigeminal ganglion (also called semilunar ganglion) consists of the cell bodies of pseudo-unipolar neurons with their proximal axons innervating the ipsilateral brainstem trigeminal complex 
(BTC) (Vincent, 1913; Ma and Woolsey, 1984) and their distal axons innervating the vibrissae follicles. Each ganglion cell innervates only one whisker follicle (Fitzgerald, 1940; Zucker and Welker, 1969; Dykes, 1975; Gibson and Welker, 1983a; Rice et al., 1986; Lichtenstein et al., 1990). The trigeminal ganglion is somatotopically organized with caudal arcs represented dorsally, and dorsal rows represented medially (Zucker and Welker, 1969; Lichtenstein et al., 1990). Early studies indicate that a great majority of the ganglion cells are slowly adapting (Fitzgerald, 1940; Kerr and Lysak, 1964; Zucker and Welker, 1969; Lichtenstein et al., 1990, but see Pubols et al., 1973; Gibson and Welker, 1983b). The rapidly adapting ganglion cells have generally higher velocity thresholds (Zucker and Welker, 1969; Lichtenstein et al., 1990). Different trigeminal ganglion units show various tuning properties, with evidence suggesting sensitivity to the following parameters: amplitude, frequency, duration, velocity, acceleration and direction of whisker deflections/motion (Fitzgerald, 1940; Kerr and Lysak, 1964; Zucker and Welker, 1969; Hahn, 1971; Pubols et al., 1973; Dykes, 1975; Gibson and Welker, 1983a,b; Lichtenstein et al., 1990). These neurons are highly sensitive to whisker deflection with over $50 \%$ of units responding to $<1^{\circ}$ of whisker deflection (Gibson and Welker, 1983a). The spontaneous activity of these units is considered to be zero (Zucker and Welker, 1969; Gibson and Welker, 1983a; Lichtenstein et al., 1990), and any discharge is potentially attributed to the high sensitivity of the units to tiny movements such as pneumatic vibrations, mechanical hysteresis of hair shaft, or tissue damage caused by microelectrode penetration (Gibson and Welker, 1983a).

\subsection{Brainstem Trigeminal Complex (BTC)}

Traditionally, the whisker-recipient trigeminal complex in the brainstem is subdivided into the principal sensory nucleus ( $\operatorname{PrV})$ and the spinal nucleus $(\mathrm{SpV})$. The latter is further subdivided rostro-caudally into 3 sub-nuclei: oralis ( $\mathrm{SpVo}$ ), interpolaris (SpVi) and caudalis (SpVc) (Arvidsson, 1982; Ma and Woolsey, 1984). Trigeminal nuclei neurons receive inputs from trigeminal ganglion cells and form discrete aggregated neuronal clusterscalled barrelettes-in each nucleus except for SpVo (Erzurumlu and Killackey, 1980; Durham and Woolsey, 1984; Bates and Killackey, 1985; Chiaia et al., 1991; Ma, 1991; Jacquin et al., 1993). Brainstem barrelettes preserve the somatotopic organization of whiskers on the mystacial pad (Belford and Killackey, 1979; Hayashi, 1980; Arvidsson, 1982). Each barrelette is about $55 \mu \mathrm{m}$ in diameter and $1.2 \mathrm{~mm}$ long along the rostro-caudal direction and contains 160-200 neurons (Timofeeva et al., 2003). The PrV and SpVi sub-nuclei provide the majority of the projections to the thalamus. Similar to first-order neurons in trigeminal ganglion, the more sensitive BTC units (with low velocity thresholds) were slowly adapting, whereas the less sensitive units (high velocity thresholds) were rapidly adapting.

A majority of PrV barrelette neurons have barrelette-bounded dendritic trees (Jacquin et al., 1993; Veinante and Deschênes, 1999). These neurons mainly project into single barreloidsneuronal aggregates representing individual whiskers-of the ventro-posterior medial nucleus (VPM) in the contralateral thalamus (Jacquin et al., 1988; Veinante and Deschênes, 1999).
Other groups of neurons in $\mathrm{PrV}$ with large multipolar somata and expansive dendritic branches spread over multiple barrelettes (Jacquin et al., 1988; Jacquin and Rhoadesi, 1990; Veinante and Deschênes, 1999), and also respond to multiple whiskers. This population mainly projects into the posterior thalamic nucleus (POm) in thalamus, tectum, superior colliculus, zona incerta, the medial part of the medial geniculate nucleus (MGm), inferior olive and medial dorsal part of VPM (VPMdm) (Huerta et al., 1983; Bruce et al., 1987; Bennett-Clarke et al., 1992; Van Ham and Yeo, 1992; Williams et al., 1994; Veinante and Deschênes, 1999). The electrophysiological studies identified two broad classes of neurons in PrV; tonic neurons which represent a single whisker, and phasic units which are driven by single or multiple whiskers (Shipley, 1974; Veinante and Deschênes, 1999; Minnery and Simons, 2003; Minnery et al., 2003).

Neurons in SpVi spread their dendritic arbors into a broader area across multiple barrelettes, and thus respond to multiple whiskers (Woolston et al., 1982; Jacquin et al., 1986). These neurons project to different brain areas, such as ventrobasal complex (mainly ventro-lateral VPM, VPMvl), the zona incerta, superior colliculus, medial geniculate nucleus, cerebellum and spinal cord (Erzurumlu and Killackey, 1980; Huerta et al., 1983; Silverman and Kruger, 1985; Jacquin et al., 1989; Van Ham and Yeo, 1992; Williams et al., 1994). SpVc also projects to VPMvl similar to the thin axons of SpVi. SpVo sends a few axons only to POm (Veinante et al., 2000).

\subsection{Thalamus}

VPM, POm and the intralaminar thalamic nuclei form the major thalamic targets of second-order neurons of brainstem trigeminal complex (Williams et al., 1994; Diamond, 1995; Veinante and Deschênes, 1999). The vibrissae representation area in VPM is somatotopically organized into discrete finger-like structures, called barreloids (van der Loos, 1976). Barreloids are oblong cylinder-like structures, with a length of $500-900 \mu \mathrm{m}$ and contain 250 to 300 neurons each (van der Loos, 1976; Saporta and Kruger, 1977; Land et al., 1995; Timofeeva et al., 2003; Oberlaender et al., 2012). The size of the barreloids is positively correlated with the length of whiskers (Haidarliu and Ahissar, 2001). Cells within a barreloid have receptive fields composed of one principal and several surrounding whiskers (Friedberg et al., 1999). POm is more homogeneous than VPM, with no barreloid-like structures. However, there is evidence that POm is organized topographically (Diamond et al., 1992; Alloway et al., 2003). Compared to VPM cells, the receptive field of POm neurons is larger (6-8 whiskers) (Diamond et al., 1992). Moreover, POm neurons show a weaker response to single whisker deflections than VPM neurons do, and unlike VPM neurons, POm neurons exhibit less preference to a particular principal whisker (Diamond et al., 1992). Instead, POm neurons are strongly driven by simultaneous disturbance of multiple whiskers.

Thalamic barreloids receive three main inputs:

1. an ascending excitatory input from the principal trigeminal nucleus $(\mathrm{PrV})$, 
2. an excitatory corticothalamic input from the barrel field in the primary somatosensory cortex (SI),

3. an inhibitory input from the thalamic reticular nucleus.

In all of these pathways, terminal fields of axons are mainly confined to the barreloid representing the corresponding principal whisker of their receptive field (Williams et al., 1994; Veinante and Deschênes, 1999; Desilets-Roy et al., 2002; Varga et al., 2002). The distal dendritic arbors of a proportion of VPM cells, however, spread in the surrounding barreloids, leading to a cross-whisker interaction (Varga et al., 2002). In contrast to the sensory-thalamic nuclei for other modalities, there are few, if any, dendrodendritic synapses and no local axon collaterals and inhibitory interneurons in rat VPM (Barbaresi et al., 1986; Harris, 1986).

Afferents of VPMdm neurons of thalamic barreloids arborize in the corresponding neuronal aggregates-barrels-in layer IV of primary somatosensory cortex and form a one-to-one connection between the VPM barreloids and cortical barrels (Herkenham, 1980; Jensen and Killackey, 1987; Chmielowska et al., 1989; Lu and Lin, 1993). Multi-barrel projections of VPM neurons have never been observed. However, some axonal innervations into septal regions surrounding the barrels were found. Thalamic reticular nucleus and the upper part of layer VI of barrel field in SI are innervated by collaterals of the ascending projections from VPM (Jones, 1975; Herkenham, 1980; Jensen and Killackey, 1987; Chmielowska et al., 1989; Lu and Lin, 1993). The VPMvl neurons do not directly project to the barrels. They receive presynaptic inputs from the caudal division of $\mathrm{SpVi}$ and branch their axons in the secondary somatosensory cortex (SII) as well as septal and dysgranular zone in SI (Pierret et al., 2000) and form the extralemniscal pathway (Yu et al., 2006). An additional ascending pathway parallel to lemniscal pathway originates from multi-whisker PrV neurons passing through the head of the thalamic barreloids (Urbain and Deschênes, 2007). The neurons in the head of barreloids have multi-whisker receptive fields, innervate layer 4 septa and receive corticothalamic feedback from layer 6 of vibrissal MI (Urbain and Deschênes, 2007; Furuta et al., 2009). Hence it suggests this pathway is involved in relaying information related to the phase of whisking.

POm projects to almost all sensory-motor areas of the neocortex, including the primary somatosensory, secondary somatosensory (SII), perirhinal, insular and motor cortices, and to a lesser extent to thalamic reticular nucleus (Deschênes et al., 1998). The laminar distribution of the terminal fields of POm projection to cortex are mainly to layers Va and I (Deschênes et al., 1998). Similarly, POm axon terminals in SI are distributed from upper layer $\mathrm{V}$ to layer $\mathrm{I}$ of the dysgranular zone and interbarrel septa, as well as in layers $\mathrm{V}$ and I of the barrels (Herkenham, 1986; Koralek et al., 1988; Lu and Lin, 1993; Deschênes et al., 1998).

The thalamic reticular nucleus (TRN) with ventrobasal thalamic nuclei forms an inhibitory feedback loop which is believed to play role in thalamic spindling (Steriade et al., 1985; Fuentealba and Steriade, 2005), sleep-related thalamocortical oscillations (Steriade et al., 1993; Pinault, 2004; Fernández et al., 2018b), arousal (Steriade et al., 1986, 1993; Lewis et al., 2015), and selective attention (Skinner and Yingling, 1977; Crick, 1984). Optogenetic activation of TRN switches the thalamocortical firing pattern from tonic to bursting and enhances cortical spindles and delta waves (Halassa et al., 2011; Lewis et al., 2015). Neurons in the reticular nucleus receive vibrissae-related input from cortical Layer VI neurons in SI (Bourassa et al., 1995), collaterals from thalamocortical neurons in VPM and POm (Harris, 1987), as well as inputs from neighboring neurons in reticular nucleus (Landisman et al., 2002). In turn, they send their GABAergic inhibitory projections back to ventrobasal nucleus and POm (Scheibel and Scheibel, 1966; Pinault et al., 1995; Lam and Sherman, 2007). These inhibitory back-projections can account for the inter-barreloid inhibition in VPM (Desilets-Roy et al., 2002; Lavallée and Deschênes, 2004). While the topographic organization of the reticular neurons that project to VPM is somatotopic, no somatotopic map was found in the reticular neurons projecting to POm (Pinault et al., 1995).

In addition to thalamic reticular nucleus, a group of thalamic nuclei-termed extra-reticular inhibitory system-innervate POm with prominent GABAergic inhibitory projections (Bokor et al., 2005; Lavallée et al., 2005). The extra-reticular inhibitory system includes the anterior pretectal nucleus (APT) (Bokor et al., 2005), zona incerta (Barthó et al., 2002; Trageser and Keller, 2004; Lavallée et al., 2005) and pars reticulate division of substantia nigra (Buzsaki, 2009). Zona incerta (ZI) and APT are reciprocally connected, both project to $\mathrm{PO}$ and brainstem motor centers and receive layer $\mathrm{V}$ cortical inputs (Terenzi et al., 1995; May et al., 1997). ZI receives direct whisker input from both PrV and SpVi (Kolmac et al., 1998; Simpson et al., 2008) in addition to input from SI (Mitrofanis and Mikuletic, 1999; Barthó et al., 2007). Neurons in the dorsal and ventral divisions of ZI exhibit multi-whisker receptive fields (Nicolelis et al., 1992) with partial somatotopy in dorsal division and a complete somatotopic organization in ventral division (Nicolelis et al., 1992; Shaw and Mitrofanis, 2002). The ventral division of the zona incerta (ZIv) receives the main input from SpVi (Kolmac et al., 1998) and serves as a relay by feed-forward GABAergic inhibition of thalamocortical neurons in higher order thalamic nuclei including the paralemniscal pathway and POm for whisker-related motor activity (Trageser and Keller, 2004; Lavallée et al., 2005). The activation of vibrissal motor cortex suppresses vibrissal responses in ZIv (Urbain and Deschênes, 2007), providing a dis-inhibition mechanism for sensory gating in higher order thalamic nuclei during whisker-related motor activity and active touch. For a thorough review refer to Mitrofanis (2005).

\subsection{Barrel Field Cortex}

The cortical vibrissae representation in rodents is formally referred to as the posterior-medial barrel sub-field (PMBSF) and occupies about $20 \%$ of the somatosensory cortex (Zucker and Welker, 1969; Welker, 1971). The cortex is organized in 6 layers (Figure 2). In rodents, Layer IV of the vibrissae region of primary somatosensory cortex-referred to as the granular zone-contains anatomically distinguishable clusters of neurons called "barrels" (Woolsey and van der Loos, 1970). 


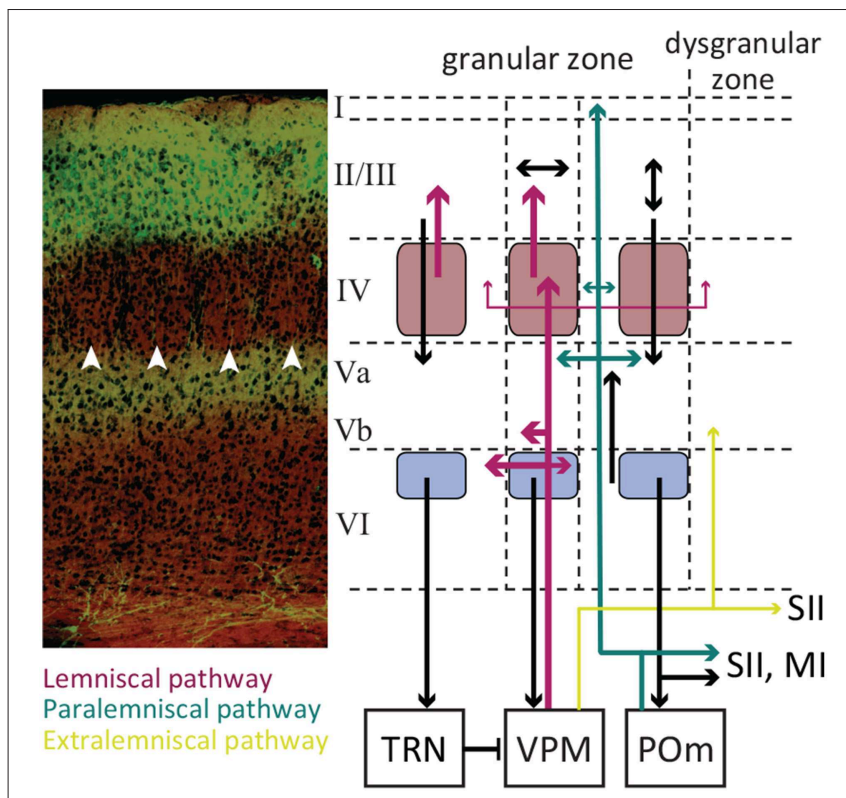

FIGURE 2 | The laminar organization of SI. A coronal section of the somatosensory cortex with cresyl violet Nissl Staining (left panel). The white arrowheads indicate barrels in layer IV. Excitatory neurons in layer II/III are GFP labeled with their terminals in Layer Va. The laminar pathway containing glutamatergic excitatory projections from VPM to layer IV and sparsely to layers $\mathrm{Vb}$ and $\mathrm{VI}$ (labeled red). The paralaminar pathway containing the projections from POm to layer Va and I (labeled cyan). The pink boxes represent the barrels, and the light purple boxes represent infrabarrels. Adopted from Petersen (2007) and modified. Immunohistology and confocal microscopy image by Ehsan Kheradpezouh and Mehdi Adibi.

Each elliptically shaped barrel is approximately $0.3-0.5 \mathrm{~mm}$ in maximal diameter (Hodge et al., 1997) and contains an average of 2500 neurons (Woolsey and van der Loos, 1970; Lee and Woolsey, 1975; Jones and Diamond, 1995). Barrels are somatotopically arranged in an identical order as the whiskers on the snout, with the most dorsal posterior whiskers being represented by the most lateral posterior barrels (Woolsey and van der Loos, 1970). Neurons within each barrel produce their strongest and fastest response to the stimulation of the anatomically-associated whisker, also known as the "principal" whisker (Welker, 1971). There is a precise one-to-one connection between thalamic barreloids and cortical barrels, with no evidence of a multi-barrel innervation by thalamocortical axons (Bernardo and Woolsey, 1987; Chmielowska et al., 1989; Agmon et al., 1995; Land et al., 1995). In rats, there are sparsecelled regions between barrels called septa (Woolsey and van der Loos, 1970; Welker and Woolsey, 1974). Inter-barrel septa together with regions surrounding the barrel field form the dysgranular zone.

There are two main types of neurons in layer IV barrels: spiny stellate and star-pyramidal excitatory neurons, and GABAergic interneurons. Both excitatory and inhibitory neurons receive direct inputs from VPM. Neurons in layer IV heavily project into supragranular layer II/III within the same cortical column (along the barrel). Septal neurons project above septum to layer II/III and to some extent coarsely to surrounding barrels, secondary somatosensory cortex (SII) and primary motor cortex (Feldmeyer et al., 1999; Kim and Ebner, 1999; Petersen and Diamond, 2000; Chakrabarti and Alloway, 2006). Some layer IV barrel axons innervate into the adjacent barrels as well (Kim and Ebner, 1999; Petersen and Diamond, 2000; Brecht and Sakmann, 2002). The targets of layer II/III neurons include the adjacent barrel layer II/III, layer V, primary and secondary motor cortices, secondary somatosensory cortex, dysgranular zone, perirhinal temporal association cortex, dorsolateral striatum and the contralateral SI (Koralek et al., 1990; Hayama and Ogawa, 1997; Kim and Ebner, 1999; Yamashita et al., 2018). The laminar organization of neurons along a barrel form functional barrel columns across cortical layers which mainly represent the barrel's principal whisker.

Thalamic afferents innervate layer $\mathrm{Vb}$ and $\mathrm{VI}$ neurons concurrently to layer IV neurons (Constantinople and Bruno, 2013). Their synapses with layer V pyramidal neurons reliably elicit action potentials (Constantinople and Bruno, 2013). Axons of the layer $\mathrm{V}$ pyramidal neurons ramify extensively within this layer with ascending collaterals targeting the supragranular layers and descending collaterals projecting to infragranular layer VI (Thomson and Bannister, 2003; Lübke and Feldmeyer, 2010; Feldmeyer, 2012; Ramaswamy and Markram, 2015). Layer $\mathrm{Va}$ is predominantly populated by slender-tufted pyramidal neurons characterized by their slender apical dendrites, while layer $\mathrm{Vb}$ is predominantly populated by thick-tufted pyramidal neurons characterized by pyramidal-like somas and thick apical dendrites and the untufted pyramidal cells (Ramaswamy and Markram, 2015). The pyramidal neurons in layer Va (both slender and thick-tufted) may function as integrators of lemniscal and paralemiscal thalamic pathways through monosynaptic connections with layer IV spiny stellate neurons (Feldmeyer et al., 2005). The layer Vb thick-tufted pyramidal neurons mainly project to anterior midbrain and thalamic nuclei, including the posterior thalamus, ZI and APT. These projections maintain the somatotopic organization beyond the cortex (Sumser et al., 2017). For a detailed recent review of the neuroanatomy and physiology of the layer V refer to Ramaswamy and Markram (2015).

Layer VI is the main source of corticothalamic feedback projections (Bourassa et al., 1995; Feldmeyer, 2012). Corticothalamic neurons, in addition to projections to sensory thalamic nuclei, ramify both excitatory and inhibitory neurons in layer IV as well as pyramidal neurons in layer Va (Feldmeyer, 2012; Harris and Mrsic-Flogel, 2013; Kim et al., 2014). Paired whole-cell recording (Lefort et al., 2009) and laser scanning photo-release of caged glutamate (Hooks et al., 2011) revealed layer VI inter-laminar input and output are weak. However, repetitive optogenetic excitation of layer VI corticothalamic neurons evokes action potentials in layer Va pyramidal neurons as well as fast-spiking interneurons in both layer IV and Va by activating facilitating synapses (Kim et al., 2014), while the overall effect on layer IV excitatory neurons is weak excitation or disynaptic inhibition (Kim et al., 2014). Layer VIa corticothalamic neurons form aggregated barrel-like structures (called infrabarrels) organized somatotopically align with the layer VI barrels (Crandall et al., 2017). Corticocortical 
neurons, on the other hand, predominantly populate between infrabarrels. By optogenetic stimulation of VPM and POm thalamic nuclei, Crandall et al. (2017) found VIa corticocortical neurons receive strong synaptic input from both VPM and POm, whereas corticothalamic neurons exhibit weaker responses to VPM input and little response to POm. The receptive field properties of neurons in the barrel field are different across layers. The receptive fields in general have an excitatory center and excitatory surround structure; cortical neurons respond vigorously to the corresponding principal whisker as well as to the adjacent/surrounding whiskers with a weaker and delayed response (Simons, 1978; Armstrong-James and Fox, 1987). However, septal neurons similar to their presynaptic POm neurons, respond to multiple whiskers without preference to a certain whisker as principal (Armstrong-James and Fox, 1987; Brecht and Sakmann, 2002). Consistent with their pattern of connectivity, layer II/III neurons, show a broader receptive field with a lower response magnitude (Ito, 1985; ArmstrongJames and Fox, 1987; Armstrong-James et al., 1992). Synaptic integration in layer $\mathrm{V}$ neurons is more complex, as these neurons receive input from layers II/III (Reyes and Sakmann, 1999), IV (Feldmeyer et al., 2005; Schubert et al., 2006), from other pyramidal neurons in the infragranular layers (Markram et al., 1997; Schubert et al., 2001), as well as substantial direct thalamic input (Bureau et al., 2006). This leads to broad receptive fields and sometimes whisker non-specific response profiles (Sachdev et al., 2001). For a more detailed review on SI laminar organization refer to Ahissar and Staiger (2010). Also, for a review on the functional organization of barrel cortex refer to Petersen (2007).

Across all cortical laminae, increasing the velocity/acceleration of stimuli applied to the principal whisker increased the amplitude of excitatory post synaptic potentials (EPSPs) and decreased their latency to peak (Wilent and Contreras, 2004). The changes in the EPSP were accompanied by a transient increase in the spiking activity of cortical neurons (Simons, 1978; Ito, 1985; Pinto et al., 2000; Arabzadeh et al., 2003; Wilent and Contreras, 2004; Adibi and Arabzadeh, 2011), typically followed by a rapid decline (within 10-20 $\mathrm{ms}$ of the response onset) to a lower level of tonic spiking rate. The synaptic response of supragranular (layer II/III) and infragranular (layer V and VI) neurons was on average delayed with respect to that of the granular (layer IV) neurons (Brecht and Sakmann, 2002; Brecht et al., 2003; Manns et al., 2004; Wilent and Contreras, 2004, but see Constantinople and Bruno, 2013). The peak of the spiking response of Layer IV neurons was followed by infragranular neurons' response peak and then by the response peak of layer II/III neurons (Wilent and Contreras, 2004). Layer IV neurons exhibit a short integration window of a few milliseconds compared to other layers. These findings suggest that layer IV neurons function as coincidence detectors, whereas supra- and infragranular circuits function as input integrators (Wilent and Contreras, 2004; Brecht, 2007). Layer V neurons are proposed to integrate lemniscal and paralemniscal inputs in addition to inputs from most or all cortical layers (Brecht, 2007). Layer IV, III and II, on the contrary, might operate as functionally segregated circuits contributing to separate lemniscal and paralemniscal processing streams (Brecht, 2007).

The sequence of cortical activation across layers is consistent with interlaminar interacortical local field potential recordings and current source analysis which exhibit early current sinks in layer IV followed by activation of layers II/III and V (Di et al., 1990; Agmon and Connors, 1991; Kenan-Vaknin and Teyler, 1994). Multi-electrode array electrophysiology from SI neurons revealed whisker deflection stimulation quenches trial-by-trial variability (Adibi et al., 2013b); the Fano factor, defined as the ratio of the variance of neuronal responses to their average, decreased as the stimulus intensity (and hence the population activity) increased (Figures 3A,B). This decrease is consistent with previous findings in areas V4 (Cohen and Newsome, 2009) and MT (Uka and DeAngelis, 2003; Osborne et al., 2004), premotor cortex (Churchland et al., 2006), and superior temporal sulcus (Oram, 2011) of monkeys (for a detailed review see Churchland et al., 2010). Stimulation quenches the correlation in trial-to-trial variability between neurons (noise correlation) (Figures 3C,D). Noise correlation is usually characterized in terms of the correlation coefficient of the spike counts for pairs of neurons. Using principal component analysis of neuronal responses, Adibi et al. (2013b) extended this measure to neuronal populations of larger than 2 neurons (see Figure 3E). The functional connectivity map constructed based on the strength of pairwise correlations of ongoing spontaneous activity of urethane-anesthetized rats recorded using $10 \times 10$ array of electrodes predicted the anatomical arrangement of electrodes on the sensory cortex (Sabri et al., 2016). Neurons with stronger correlations to the population during episodes of spontaneous activity, carried higher information about the sensory stimuli in their evoked response (Figure 3F). It is, however, not clear whether this higher level of correlations is due to common input from thalamus or originates from the cortical circuitry. Moreover, the correlation profile of electrode pairs during spontaneous activity predicted both signal and noise correlations (Adibi et al., 2014) during sensory stimulation (Figures 3G,H).

It has been demonstrated that barrel cortex neurons in anesthetized rats robustly encode the velocity of whisker motion (Simons, 1978; Pinto et al., 2000; Arabzadeh et al., 2003, 2004; Estebanez et al., 2012). The whisker motion features that these neurons encode form a common low-dimensional feature subspace of whisker motion, comprising linear combination of whisker velocity and position, and to a lesser extent whisker acceleration (Maravall et al., 2007; Estebanez et al., 2012). Estebanez et al. (2012) recently demonstrated that the feature encoding properties of cortical neurons differ depending on the level of spatial correlation in multi-whisker sensory stimuli. In addition to velocity, cortical neurons in the whisker-related area of SI exhibit directional selectivity (Simons, 1978; Simons and Carvell, 1989; Bruno and Simons, 2002; Wilent and Contreras, 2005; Puccini et al., 2006; Kremer et al., 2011).

The feedback projections from infragranular layers to the vibrissae-related thalamic sensory nuclei consist of three main routes: 

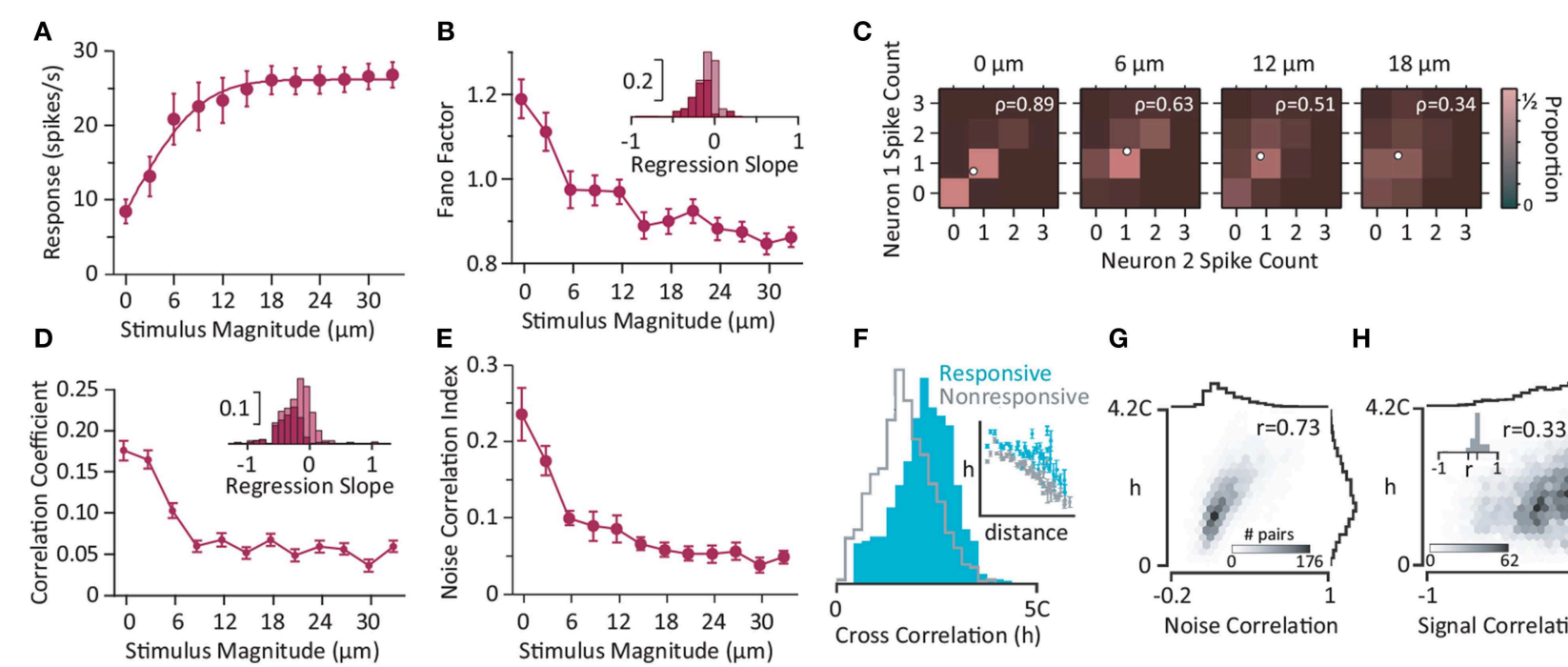

G

H

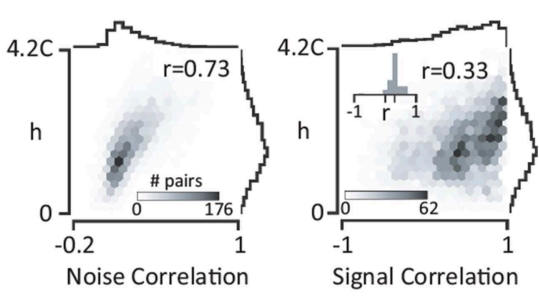

FIGURE 3 | Neural activity in somatosensory cortex. (A) The population activity increases with the magnitude of whisker deflection stimulation (single-cycle sine-wave at $80 \mathrm{~Hz}$ ). Error bars represent the standard error of means across populations with more than five simultaneously recorded units $(n=8)$. (B) Trial-to-trial variations in neuronal response (in terms of Fano factor) as a function of stimulus intensity for single neurons $(n=64)$. The inset depicts the histogram of the linear regression slope of the Fano factor with respect to the $z$-scored neuronal activity for individual neurons. The dark bars correspond to recordings with a significant linear regression $(p<0.05)$. (C) Color indicates the proportion of joint spike counts for a pair of simultaneously recorded neurons. White circles indicate mean spike counts for each stimulus. The Pearson's correlation coefficient of the spike counts is indicated by $\rho$ for each panel. (D) The mean Pearson's correlation coefficient across all possible pairs of neurons $(n=245)$ as a function of stimulus intensity. Error bars indicate standard error of means. The inset depicts the histogram of regression slopes of noise correlation against average firing rate for pairs of neurons. Dark bars indicate the cases with significant linear regression $(p<0.05)$. (E) The noise correlation index $($ Adibi et al., 2013b) as a function of stimulus magnitude averaged across populations containing at least five simultaneously recorded neurons (data from A). Error bars are standard error of mean across populations $(n=8)$. Most of the neurons exhibit a negative slope indicating Fano factor (B) and noise correlations decrease with firing rate. $(\mathbf{F})$ The strength of correlation, denoted by h: the peak of the cross correlation of a pair of electrodes relative to the chance level (denoted by C). Electrodes were divided into two groups of "Responsive" and "Nonresponsive" based on the median of the mutual information between neuronal responses and whisker stimulation. The distribution of $\mathrm{h}$ values for Responsive pairs (where both electrodes were from the Responsive group; cyan) and Nonresponsive pairs (where both electrodes in a pair were from the Nonresponsive group; gray). The inset depicts the average and standard error of means of strength of correlation, h, across electrode pairs as a function of their distance for each category. (G) The histogram shows the joint distribution of $h$ values and noise correlations. $r$ represents the correlation coefficient. (H) Same as (G), but for signal correlation. Inset depicts the histogram of $r$ value calculated for groups of electrode pairs with identical distance. The distribution of $r$ values is positive with a mean of 0.3 indicating that the positive correlation between $\mathrm{h}$ and signal correlation is independent of the distance between electrodes and is present across all distances. (A-E) are based on Adibi et al. (2013b), and (F-H) are from Sabri et al. (2016).

1. Neurons in the upper part of layer VI of a barrel exclusively project to the corresponding barreloid in VPM (Bourassa et al., 1995; Land et al., 1995) forming a reciprocal barreloidbarrel connection.

2. Neurons in the lower part of layer VI project to POm and also a major proportion of these axons make collaterals in VPM to form rostro-caudal rod-like bands representing an arc of vibrissae (Hoogland et al., 1987; Bourassa et al., 1995).

3. The corticothalamic projections of layer $\mathrm{V}$ cells exclusively terminate in POm (Bourassa et al., 1995).

The axons originated from layer VI along the inter-barrel septa exclusively target POm (Bourassa et al., 1995). The Layer VI corticothalamic axons, but not those of layer $\mathrm{V}$ give off collaterals in the reticular nucleus while traversing it (Bourassa et al., 1995; Deschênes et al., 1998).

The primary somatosensory cortex projects to the secondary somatosensory cortex, the primary motor cortex (MI), thalamus sensory nuclei, superior caliculus and dorsolateral neostriatum (White and DeAmicis, 1977; Carvell and Simons, 1986, 1987; Welker et al., 1988; Deschênes et al., 1998; Alloway et al., 2006;
Chakrabarti and Alloway, 2006; Hattox and Nelson, 2007; Larsen et al., 2007). Also, the barrel cortices on two hemispheres are linked by a callosal connection (White and Czeiger, 1991). In turn, primary somatosensory cortex receives inputs from the secondary somatosensory cortex and motor cortex (Carvell and Simons, 1987; Kim and Ebner, 1999). Unlike in primates (Hsiao et al., 1993; Jiang et al., 1997; Iwamura, 1998; Mima et al., 1998; Karhu and Tesche, 1999; Salinas et al., 2000; Romo et al., 2002), little is known about the functional properties of the secondary somatosensory cortex in rodents, and this knowledge is limited to anesthetized preparations (Carvell and Simons, 1986; KwegyirAfful and Keller, 2004).

\subsection{Parallel Ascending Subcortical Routes for Whisking and Touch Signals to Cortex}

The whisker information from trigeminal complex is channeled to cortex through three parallel pathways (Pierret et al., 2000; Yu et al., 2006, also see Figures 1, 2):

1. The lemniscal pathway is the major pathway through which the touch signal is channeled to cortex. This pathway includes 
ipsilateral PrV barrelettes to contralateral VPMdm barreloids to cortical barrel columns layer IV and sparsely to Layer VI in SI. The lemniscal pathway conveys a combination of touch and whisking signals and is speculated to represent the "what" pathway (analogous to the ventral stream in the visual system).

2. The paralemniscal pathway channels the sensory information from rostral part of alaminar spinal trigeminal nucleus (nucleus interpolaris or $\mathrm{SpVi}$ ) into the thalamic posterior medial nucleus (POm), and then to the following cortical areas: layer I and Va of SI, the septal regions, SII, MI and superior colliculus. The paralemniscal pathway primarily conveys whisking signals, which can be employed to form sensory-motor coordination and positional reference signals during exploration/whisking (Ahissar et al., 2000; Kleinfeld et al., 2006). Hence the paralemniscal pathway is speculated to represent the "where" system in somatosensation in rodents (analogous to the dorsal stream in the visual system).

3. The extralemniscal pathway conveys touch information from SpVc and caudal division of SpVi to VPMvl thalamus and then to SII and the septal regions of SI cortex.

The lemniscal and paralemniscal pathways interact; the lemniscal pathway has been shown to suppress the paralemniscal pathway through cortically-activated rapid GABAergic inhibitory projections of zona incerta to POm (Lin et al., 1990; Nicolelis et al., 1992; Power et al., 1999).

\section{PHYSIOLOGY AND FUNCTION}

\subsection{Modes of Whisker-Mediated Sensation}

As in vision where controlled eye movements-saccadesenhance the efficacy of the visual system to browse the environment and extract relevant visual information, rodents sweep their mystacial vibrissae to scan the environment and collect behaviorally-relevant information. A body of literature referred to this purposively information-seeking manipulation of sensory apparatus as "active sensing" (Gibson, 1962; Aloimonos et al., 1988; Aloimonos, 1990; Szwed et al., 2003, 2006; Mitchinson et al., 2007; Grant et al., 2009; Sullivan et al., 2012). In the realm of engineering, however, "active sensing" against "passive sensing" means emitting energy (e.g., in electromagnetic form as in radar or in mechanical form as in sonar) and sensing the reflections of the emitted signal to obtain information about the medium/environment. To avoid this ambiguity, here, I follow the terminology as in Diamond and Arabzadeh (2013) which categorize the whisker-mediated perception in rodents into two modes: "generative" and "receptive."

Whisking is the self-generated exploratory whisker motion through which rodents sense their surrounding environment in the "generative mode." This generative mode of whisking is used in the perception of surface textures, identification of objects and shapes, estimation of distances and localization of objects. As a whisker comes in contact with an object or palpates the object, its instantaneous motion changes following every contact and release from the surface with high acceleration and high velocity-stick-slip events. The sequence of these stickslip events along with the self-generated component of the whisker motion uniquely reconstructs the kinetics of surface and determines the texture of a surface, or the shape or location of an object. A body of research has focused on quantification of behavioral capacities and characterization of whisker motion and its consecutive neuronal activity in the generative mode. These include a variety of behavioral tasks or simulated conditions such as texture discrimination (Carvell and Simons, 1990; GuićRobles et al., 1992; Prigg et al., 2002; Arabzadeh et al., 2005; von Heimendahl et al., 2007; Diamond et al., 2008; Itskov et al., 2011; Morita et al., 2011; Zuo et al., 2011), identification of shape and size of objects (Brecht et al., 1997; Harvey et al., 2001; Polley et al., 2005), distance, gap and aperture width detection (Hutson and Masterton, 1986; Guic-Robles et al., 1989; Harris et al., 1999; Jenkinson and Glickstein, 2000), object localization (Knutsen et al., 2006; Mehta et al., 2007; Ahissar and Knutsen, 2008; Knutsen and Ahissar, 2009; O'Connor et al., 2010) and natural exploratory whisking (Fee et al., 1997; Kleinfeld et al., 2002, 2006; O’Connor et al., 2002; Berg and Kleinfeld, 2003; Szwed et al., 2003; Ganguly and Kleinfeld, 2004; Knutsen et al., 2005). For other paradigms, such as width discrimination described in (Krupa et al., 2001) whisking may not be essential. However, I categorized such behavioral tasks in the generative mode as they require controlled head positioning and movements.

As in vision where fixating the gaze on a focal target provides more accurate visual information, in receptive mode, rats can immobilize their vibrissae to achieve efficient vibro-tactile signal collection from a mobile object. In vision, saccades during a fine visual task such as counting degrade the performance. Similarly, there is behavioral evidence that self-generated whisker motion reduces the rodent's performance when detecting vibrations (Ollerenshaw et al., 2012). This aspect of whisker-mediated sensation is less investigated in the literature (Hutson and Masterton, 1986) and research has been mainly limited to headfixed rodents performing a go/no-go licking task (Stüttgen and Schwarz, 2008, 2010; Gerdjikov et al., 2010; Schwarz et al., 2010).

Recent studies revealed that the response dynamics of cortical neurons changes with the mode of sensation and the behavioral state (Fanselow and Nicolelis, 1999; CastroAlamancos, 2004; Crochet and Petersen, 2006; Ferezou et al., 2006, 2007). The response of cortical neurons to whisker stimuli was suppressed in the generative mode compared to the receptive mode or quiescent state (Castro-Alamancos, 2004; Crochet and Petersen, 2006; Ferezou et al., 2006, 2007; Crochet et al., 2011). Likewise, neurons in rat auditory cortex show sensory-evoked response suppression during active behavioral states (Otazu et al., 2009). Additionally, fluctuations in local field and membrane potentials of layer II/III cortical neurons exhibit prominent slow synchrony during receptive mode (Crochet and Petersen, 2006; Poulet and Petersen, 2008; Gentet et al., 2010, 2012). In the generative mode during free whisking, however, membrane potential fluctuations were suppressed and desynchronized across nearby neurons. This cortical state of desynchrony was accompanied by an increase in the spiking activity of thalamocortical neurons (Poulet et al., 2012). Cutting the sensory peripheral afferents innervating whisker follicles did not affect the generative mode response suppression and desynchrony, indicating that its origin is not 
peripheral (Poulet et al., 2012). Pharmacological inactivation of thalamocortical neurons, however, halted the generativemode desynchronization. Consistently, optogenetic stimulation of thalamocortical neurons induced similar desynchronized cortical state (Poulet et al., 2012). For further details refer to the review article by Petersen and Crochet (2013).

\subsection{Behavioral Approaches to Systems Neuroscience: Linking Circuitry and Function}

How does neuronal activity give rise to sensation and ultimately perception? To what extent does the neuronal readout match the perception of whisker vibration? In order to draw a causal link between neuronal activity and sensorimotor, perceptual, and cognitive functions, it is crucial to develop appropriate behavioral methods and combine them with requisite methods of observation and perturbation of neuronal activity. The behavioral approaches in rodent model system are either based on native forms of natural behavior such as whisking, hence require minimum training - for instance, free navigation or exploration, whisking and aperture or gap crossing (Harris et al., 1999; Jenkinson and Glickstein, 2000; Crochet and Petersen, 2006; Celikel and Sakmann, 2007; Sofroniew et al., 2014; Kandler et al., 2018)_or paradigms embedded in an artificial task and require extensive training of the animal to interact with the environment and express specific behaviors in response to events and stimuliin this context, neutral tactile stimuli such as textures, vibrations or object contacts. The body of literature mainly divides into two forms of behavioral tasks: (i) go/no-go or lick/no-lick, and (ii) two- or multiple-alternative-choice tasks.

Go/no-go (or lick/no-lick) tasks are often used in the headfixed preparation predominantly in mice and sometimes in rats (Topchiy et al., 2009; Schwarz et al., 2010; Guo et al., 2014a; Fernández et al., 2018a; Helmchen et al., 2018). It provides the mechanical stability and a fixed head position ideal for precise whisker stimulation, whisker motion tracking, eye/pupil and gesture tracking, as well as electrophysiology (for instance, intracellular recording) and imaging from cortex (two-photon calcium imaging or voltage-sensitive dye imaging). To prevent learning about timing of the reward as a confounding cue, and to minimize impulsive or anticipatory responses based on the periodicity of the sensory events and reward, go/nogo tasks usually do not have a discrete trial structure, or the initiation of a trial is at random time instances with variable delays. The proportion of the trials followed by no-go should be precisely balanced in order to minimize excessive reinforcement of spontaneous incorrect go choices (false alarms) and to avoid formation of a bias toward go or no-go choices. Other limitations of the go/no-go tasks in head-fixed preparation include no re-enforcement (reward) for correct no-go choices, suppressed vestibular signals which may play a crucial role for coordination of whisking behavior and body movements, and relying on licking behavior with highly reflexive components (Keehn and Arnold, 1960; Schaeffer and Premack, 1961; Hulse and Suter, 1968) as a representation of a cognitive goal-directed behavior. Using conditioned level-press responses, Mehta et al. (2007) found that rats with only a single whisker combine touch and whisker movement to distinguish the location of objects at different angular positions along the sweep of whisker. The other limitation of go/no-go head-fixed tasks is the lack of control over motivational factors (e.g., satiation) affecting the likelihood of go choices. The motivation can be controlled by employing a self-initiation mechanism for trials. Go/no-go paradigm is commonly used to quantify the behavioral performances for detection of a stimulus or the detection of change (Stüttgen and Schwarz, 2008; Ollerenshaw et al., 2012; Bari et al., 2013) and discrimination of two sets of stimuli, one associated with go (and hence reward), and one associated with no-go (Mehta et al., 2007; Gerdjikov et al., 2010; O’Connor et al., 2010; Chen et al., 2013). Lee et al. (2016) applied a visuo-tactile detection go/no-go task in freely moving rats with the minimum level of temporal uncertainty; upon the initiation of a trial by nose-poke into a port, the sensory cue (whisker deflection or visual flicker) appeared after a delay of either 300 or $800 \mathrm{~ms}$ each of which with equal likelihood. After stimulus onset, the rat had a 500 ms window of opportunity to elicit the go choice and collect the reward. For a hypothetically "logical" rat, the optimal strategy is to detect the sensory stimulus only at the time instance associated to the short delay $(300 \mathrm{~ms})$. Upon no detection at $300 \mathrm{~ms}$, the hypothetical rat makes an anticipatory non-sensory go choice at $800 \mathrm{~ms}$, as the hazard rate for stimulus presentation (and hence reward delivery) at $800 \mathrm{~ms}$ equals 1 (i.e., absolute certainty). This non-sensory anticipatory strategy explains the faster response time to 800 -ms stimulation compared to 300 -ms stimulation observed in (Lee et al., 2016). Additionally, this strategy predicts a higher proportion of misses for short delay stimulation and higher hit rate for the long delay stimulation (see also Lee et al., 2019). Extracellular array recording from vSI neurons during this task revealed enhanced cortical activity to whisker stimulation with higher expectancy (likelihood compared to visual stimulus) (Lee et al., 2016, 2019). This supports a plausible multiplicative gain modulation of evoked responses or alternatively an additive modulation of baseline activity. This response enhancement may be induced by expectation or attentional factors, motor preparation or sensory events related to motor output (as the task lacks a delay after stimulus presentation to withhold the go choice and to separate stimulus presentation from choice), decision processes and motor output. This is a common drawback in go/no-go, and in particular, lick/no-lick paradigms. In contrast to go/no-go tasks in which it is difficult to distinguish a lack of motivation or lapses of attention from false rejections or correct rejections, two-alternative-choice tasks provide a clear distinction of correct, incorrect, and missed trials.

Two- or multiple-alternative-choice tasks can be divided into two main categories: sensory discrimination/comparison and categorization tasks (Figure 4). In sensory discrimination tasks, every trial includes presentation of two stimuli. Discrimination/comparison tasks take two forms depending on the association of the two choices with the stimuli. In the "comparative" discrimination (Figure 4A), the task is to compare an attribute of the two stimuli against each other [e.g., roughness of textures (Carvell and Simons, 1990), frequency (Adibi et al., 2012; Mayrhofer et al., 2012), magnitude (Adibi and Arabzadeh, 

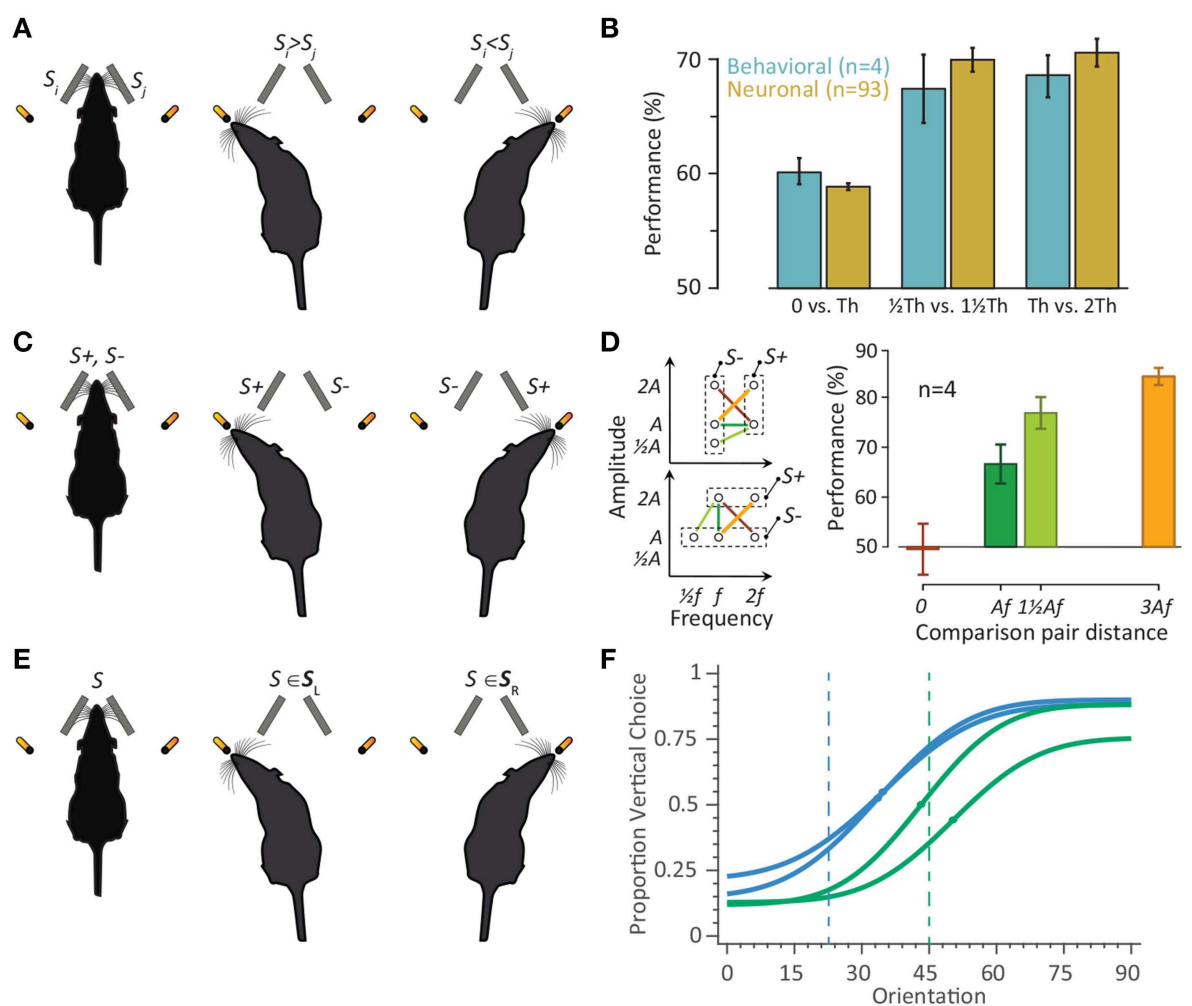

FIGURE 4 | The two-alternative-choice behavioral tasks in rodents. (A) Schematic representation of the comparative discrimination paradigm. On every trial, two vibrations $S_{i}$ and $S_{j}$ were presented. (B) Four rats were trained in the detection/discrimination task to identify the vibration with the higher amplitude. The neuronal performance is the average performance (based on the area under ROC) across single-units $(n=35)$ and multiunit clusters $(n=58)$ from Adibi and Arabzadeh (2011). For each neuron, the stimulus intensity whose detection performance was closest to $60 \%$ was chosen as detection threshold (Th). The stimuli corresponding to $\frac{1}{2}-$, $1 \frac{1}{2}-$, and 2 -fold Th were then selected for estimating the discrimination performances. The same threshold of $60 \%$ defined as detection threshold for rats. The rats performed the comparison task between $0-T h, \frac{1}{2}-1 \frac{1}{2}$ and $T h-2 T h$. Error bars indicate standard error of means across rats or neurons. (C) Schematic representation of the categorical discrimination paradigm. Stimuli were defined as either $\mathrm{S}+$ or $\mathrm{S}-$. In each trial, one of the two vibrations was $\mathrm{S}+$ and the other was S-. Having identified the S+ vibration, the rodent expressed its choice by turning toward the corresponding drinking spout. (D) (Left) Stimulus space. Each circle represents the frequency-amplitude combination of one stimulus. Two groups of rats were trained in the task. For one group (top-left), two frequencies $(f=80 \mathrm{~Hz}$ and $2 f=160 \mathrm{~Hz})$ and three amplitudes $\left(\frac{1}{2} A=8 \mu \mathrm{m}, A=16 \mu \mathrm{m}\right.$, and $\left.2 A=32 \mu \mathrm{m}\right)$ were used to generate five vibrations, and for second group (bottom-left) three frequencies $\left(\frac{1}{2} f=40 \mathrm{~Hz}, f=80 \mathrm{~Hz}\right.$ and $\left.2 f=160 \mathrm{~Hz}\right)$ and two amplitudes $(A=16 \mu \mathrm{m}$ and $2 A=32 \mu \mathrm{m})$ were used to generate five vibrations. Stimuli that were presented together and had to be discriminated (paired stimuli) are connected by lines. The right panel shows the proportion of correct trials (performance) for the corresponding four stimulus-pairs averaged across rats. Error bars are s.e.m. across rats. Re-plotted from (Adibi et al., 2012). (E) The schematic representation of the categorization paradigm. The stimuli are divided into two categories of $S_{L}$ and $S_{R}$, corresponding to left and right choices, respectively. A stimulus $S$ was presented on every trial. The rat identifies the category which stimulus $S$ belongs to. $(\mathbf{F})$ Rats were trained to categorize the orientation of a $9.8 \mathrm{~cm}$-diameter disc with alternating ridges and grooves by licking at one of the two reward spouts. Psychometric functions correspond to two rats trained to categorize orientations $0-45^{\circ}$ as horizontal, and $45-90^{\circ}$ as vertical (green), and another two rats trained to categorize orientations $0-22.5^{\circ}$ as horizontal, and $22.5-90^{\circ}$ as vertical (blue). The curves correspond to a Gaussian cumulative function fitted to data. The dots on each curve represent the perceptual decision boundary of each rat. The blue and green vertical dashed lines represent the categorization boundaries of $22.5^{\circ}$ and $45^{\circ}$, respectively.

2011; Adibi et al., 2012; Fassihi et al., 2014, 2017), or duration (Fassihi et al., 2017) of two vibrations]. Each outcome of the comparison is associated with one of the two reward ports. The two stimuli may present simultaneously at two distinct positions (e.g., two whiskers, or two sides of snout Carvell and Simons, 1990; Adibi and Arabzadeh, 2011; Adibi et al., 2012) or at one position but at distinct time instances (Fassihi et al., 2014, 2017). In the "categorical" discrimination (Figure 4C), the stimuli are divided into two categories of rewarded/target $(\mathrm{S}+)$ vs. unrewarded/distractor ( $\mathrm{S}-$ ). Each trial comprises presentation of one stimulus from each of the two categories. The task is to select the choice associated to the position of the target/rewarded stimulus (Morita et al., 2011; Adibi et al., 2012; Mayrhofer et al., 2012; Musall et al., 2014).

In the categorization tasks, the stimuli are divided into two categories, each of which associated with one of the two choices (Figure 4E). On every trial, one stimulus is presented, and the task is to identify the category to which the stimulus belongs. Categorization tasks can be considered as a discrimination/comparison task against a reference or boundary dividing the physical feature space of the stimulus into two categories. Alternatively, it can be considered as a mapping of 
individual stimuli with one of the two choices. Rodents can perform whisker-mediated tactile categorization tasks on sensory attributes such as textures (von Heimendahl et al., 2007; Zuo et al., 2011; Grion et al., 2016; Zuo and Diamond, 2019b), whisker deflection amplitude pattern (McGuire et al., 2016), aperture width (Krupa et al., 2001), location (Guo et al., 2014b; Li et al., 2015; Helmchen et al., 2018) and orientation (our recent data in Figure 4F, also see Nikbakht et al., 2018) of objects.

Discrimination and detection behavioral studies quantify the psychometric response function (the likelihood of the choices as a function of stimulus attribute) which along with the acquisition of neuronal activity allows linking the behavioral function to the neuronal activity. Comparison of the neuronal and psychophysical performances started in the late 1960s in the classic electrophysiological experiments in cat retina (Barlow and Levick, 1969; Barlow et al., 1971) and in the somatosensory cortex (Talbot et al., 1968; Mountcastle et al., 1972). Thereafter, more studies have combined psychophysical and neurophysiological experiments in order to relate neuronal responses to perception (Romo et al., 1998, 2000; Hernández et al., 2000; Salinas et al., 2000; Ress and Heeger, 2003; Luna et al., 2005; de Lafuente and Romo, 2006; Stüttgen and Schwarz, 2008) and decision making (Newsome et al., 1989; Shadlen et al., 1996; Romo et al., 2004; Hanks et al., 2006; Kiani et al., 2008). Instead of the traditional comparison of behavioral and neuronal thresholds or sensitivities, Adibi and Arabzadeh (2011) compared the non-linearity of the behavioral and neuronal response profiles to the amplitude of vibration. In a series of vibration detection and amplitude discrimination tasks, Adibi and Arabzadeh (2011) first quantified the detection threshold of both cortical neurons and rats (denoted by $T h$, Figure 4B). For near-threshold stimuli with identical amplitude difference, both the neuronal and behavioral discrimination performances surpassed the detection performances (Figure 4B). This is consistent with the accelerating nonlinearity of neurometric and psychometric functions at low stimulus intensities. The results revealed the nonlinearity in the neuronal response function predicts behavioral detection and discrimination performances. This study presents the first observation of the "pedestal effect"-frequently reported in human psychophysics-in animal literature. Using the same behavioral detection task, McDonald et al. (2014) showed rats' behavior indicated a dynamic stimulus sampling whereby stimulus sampling was continued until the stimulus was correctly identified or the rat experienced a false alarm. This is consistent with the recent evidence from texture identification task (Zuo and Diamond, 2019a,b) suggesting similar to primates, rats' choices are governed by bounded integration of primacy-weighted touch-by-touch evidence.

Previous electrophysiology studies identified the physical features of whisker motion that are encoded in the activity of cortical neurons to be the product of elemental features of whisker motion, its frequency $(f)$ and amplitude $(A)$ (Simons, 1978; Ito, 1985; Pinto et al., 2000; Arabzadeh et al., 2003, 2004). Consistently, behavioral studies revealed rats are unable to discriminate these elemental features independently of their product (Adibi et al., 2012); two groups of rats were trained to discriminate either based on the frequency or based on the amplitude of the vibrations delivered to both whisker pads The stimulus pairs with identical Af product (marked in red, Figure 4D) were not discriminable, while the other stimulus pair with the same feature difference in the physical space (marked with orange, Figure 4D) were highly discriminable. In both groups, rats' performance in discriminating two stimuli is accounted for by the difference in $A f$ but not by differences in either elemental feature $(A$ and $f)$ alone. This is consistent with the electrophysiological findings that neurons reduced the dimensionality of the stimulus from two features $(A, f)$ to a single feature: the product $A f$ (Arabzadeh et al., 2003, 2004). Af defines a real physical property: the speed of whisker motion averaged over cycles.

The bridge linking neuronal activity to perception is the readout mechanism of sensory neurons. The interlaced synaptic architecture of neural networks provides strong evidence for decoding by downstream neuronal structures based on "populations" of neurons rather than individual single neurons. Such a synaptic organization together with physiological properties of dendritic processes by which neurons receive information simulates an integration model in which the activity of neurons in the relevant population is summed with different weights. This provides a simple framework to investigate how a biologically plausible ideal observer of neuronal responses, a linear "decoder," extracts information about the stimuli. Linear decoders are simple in their structure and compatible with the architecture of the brain. With optimizing the weights, it provides an upper limit to the amount of information extractable from neuronal responses. There are two limiting factors affecting the reliability of the neuronal code for sensory stimuli: the response variability of individual neurons to a given stimulus, and covariability (noise correlation) across the neurons. In our previous studies, we characterized the neuronal response statistics in terms of neuronal variability (Fano factor) and co-variability (noise correlation) and parsed out the effect of each of these components on the coding as well as decoding efficiency of cortical populations (Adibi et al., 2013a,b, 2014). Adibi et al. (2014) further quantified the effect of noise correlations on the optimal linear decoder and characterize the cost of ignoring noise correlations during decoding.

\subsection{Motion Detection and Spatial Invariancy in Whisker-Mediated Touch System}

A majority of neurons across different layers of the rat barrel cortex exhibit multi-whisker receptive fields (Simons, 1978; Armstrong-James and Fox, 1987; Moore and Nelson, 1998; Ghazanfar and Nicolelis, 1999; Brecht and Sakmann, 2002; Brecht et al., 2003). The spatial extent of the receptive field of a cortical neuron depends on the intra-cortical connections between barrel columns (Armstrong-James et al., 1991). Anatomical studies revealed that intra-cortical inter-barrel connections are stronger between barrels within a row (Bernardo et al., 1990a,b; Hoeflinger et al., 1995), with directionally-biased fiber projections into the anterior barrel (Hoogland et al., 1987; Bernardo et al., 1990a). Additionally, intra-cortical projections 
from septal columns extend two to three barrels along the rows (Kim and Ebner, 1999). Consistently, the activity pattern of VPM and cortical neurons to single-whisker deflections is elongated along rows (Simons, 1978; Armstrong-James and Fox, 1987; Armstrong-James et al., 1992; Lee et al., 1994; Kleinfeld and Delaney, 1996). Electrophysiological studies also revealed that the multi-whisker interaction along rows and arcs is not symmetric. Suppressive two-whisker interactions have been reported to be more prominent during within-row stimulation than during within arc stimulation (Ego-Stengel et al., 2005), while within-arc multi-whisker stimulation yields more supralinear response integration (Ghazanfar and Nicolelis, 1997; EgoStengel et al., 2005). However, multi-whisker interactions are highly dependent upon the temporal order and timing of the stimulation (Shimegi et al., 1999, 2000). Estebanez et al. (2012) demonstrated that the feature encoding properties of cortical neurons changes with the level of spatial correlation in multiwhisker sensory stimuli. In addition to its anatomical and functional importance, the rostro-caudal axis is behaviorally relevant. Through exploratory behavior, rats whisk (move their vibrissae) rostro-caudally, leading to a functional asymmetry between rows and arcs; as the whiskers palpate an object, whiskers within a row contact the object successively relative to their rostro-caudal position in the row, whereas whiskers within an arc usually contact the object nearly simultaneously. Thus, a potential function of within-arc facilitatory interactions might be to boost up the contact signal which is more likely to arise from whiskers within an arc. Alternatively, the spatiotemporal multi-whisker interactions could be an indication of crosswhisker motion detection (e.g., head relative to environment and vice versa) at the level of neurons in the rat primary somatosensory cortex or secondary somatosensory cortex (Jacob et al., 2008). Simple biologically-plausible models such as the Reichardt model (Hassenstein and Reichardt, 1956; Reichardt, 1961) - a correlation detector based on temporal delays-or energy models (Adelson and Bergen, 1985) provide plausible frameworks underlying movement detection in barrel cortex. Such motion detectors are more likely to be identified in SII or in the infra-granular layers of SI where neurons have broad multi-whisker receptive fields. In addition to information about the velocity of moving objects or the ego motion, such motion detectors can provide information about the location of objects with respect to head during whisking or head movements. A recent study (Curtis and Kleinfeld, 2009) showed that barrel neurons provide a representation of the position of contacted objects in a coordinate frame that is normalized to the trajectory of the motor output (i.e., phase of whisking). Contact was encoded independently of the angular whisker position and was shown to be invariant with respect to the amplitude and frequency of whisking. The representation of contact in a coordinate system that is dynamically normalized by the motor output provides the basis for encoding the spatiotemporal properties of an externally induced movement.

Le Cam et al. (2011) demonstrated that functional principal whisker-the whisker eliciting the strongest response with the shortest latency-differed based on the direction of whisker deflection along the rostro-caudal axis. The stimulus-induced changes in the spatial structure of the receptive field of the neurons was not limited to the principal whisker, and included stimulus-dependent changes in the size, response latency and receptive field center of mass. Although the neuronal mechanisms underlying these dynamic changes are not clear, they suggest invariancy of whisker position through whisking along the rostro-caudal axis; as the rat whisks, the position of the whiskers changes along the rostro-caudal axis with respect to the head leading to potential ambiguity about the position of an object in contact with the whisker. Such a dynamic shift in the receptive fields might help to adjust the position of contact with respect to the head instead of the whisker. This position invariant information can potentially give rise to whisker-mediated coordination, and contribute to spatiotopic representations in grid cells (Hafting et al., 2005) in the entorhinal cortex, head-direction cells in classic Papez circuit (Taube, 1998) and place cells (O’Keefe, 1976; O'keefe and Conway, 1978; O'Keefe and Nadel, 1978) in parahippocampal and hippocampal cortices.

\subsection{Directional Selectivity in Whisker-Mediated Touch System}

There are several lines of evidence that cortical neurons in the whisker area of SI exhibit directional selectivity (Simons, 1978; Simons and Carvell, 1989; Bruno and Simons, 2002; Wilent and Contreras, 2005; Puccini et al., 2006; Kremer et al., 2011; Kwon et al., 2018). Direction preference is also observed in the response of thalamic and trigeminal neurons (Shosaku, 1985; Lichtenstein et al., 1990; Hartings et al., 2000; Minnery et al., 2003; Timofeeva et al., 2003; Furuta et al., 2006; Bellavance et al., 2010). Although the directional selectivity in the periphery and brainstem originates in the uneven arborization of nerve terminals around the follicle (Lichtenstein et al., 1990), directiondependent differences in the temporal profile of synaptic excitation and inhibition in barrels (Wilent and Contreras, 2005) and non-linear dendritic processes (Lavzin et al., 2012) also may contribute to the directional tuning in barrel cortex neurons. The directional selectivity decreases along the ascending whiskerto-barrel pathway. The functional and behavioral correlate of directional selectivity in the whisker-to-barrel system is not understood and it is not clear whether rats perceive the direction of vibro-tactile stimulus. However, several lines of research provide evidence against an angular selectivity readout such that leads to a sensation of direction. First, neurons with multiwhisker receptive fields in cortex and thalamus do not necessarily exhibit the same angular preference to different whiskers in their receptive field (Hemelt et al., 2010, but see Kida et al., 2005). Second, in the visual system, orientation selectivity arises from specific convergence of directionally non-tuned thalamic inputs in layer IV of striate cortex and gives rise to selectivity to more complex features along the cortical visual hierarchy. On the contrary, in the whisker-mediated touch system, directional selectivity exists in the peripheral sensory afferents innervating vibrissae follicles and gets weaker along the ascending whiskerto-barrel pathway. Thirdly, in contrast to visual system where the arrangement of neurons across the cortical surface forms a 
precise "pinwheel"-like orientation preference topographic map (Hubel and Wiesel, 1974; Blasdel and Salama, 1986; Grinvald et al., 1986; Bonhoeffer and Grinvald, 1991; Ohki et al., 2005, 2006), the evidence on a topographic directional tuning map in barrel field of SI is weak and controversial in the literature. While directional preference mapping was observed in VPM (Timofeeva et al., 2003), neurons in layer IV barrels exhibit weak direction preference map (Bruno et al., 2003; Andermann and Moore, 2006). Weak correlation between the angular tuning and position of neurons with respect to the center of barrel column was observed in layer II/III of adult rats through tetrode recording (Andermann and Moore, 2006) as well as two-photon calcium imaging (Kremer et al., 2011). However, such an angular preference spatial mapping is absent in supragranular layers in juvenile rats (Kerr et al., 2007). In layer II/III, two-photon imaging revealed orientation-specific responses were organized in a locally heterogeneous and spatially distributed manner (Kwon et al., 2018). Additionally, neurons with similar orientation preference exhibited higher correlation in their trialto-trial response variability.

Although it has been shown that rats are capable of discriminating between different orientations of an object using all of their whiskers (Polley et al., 2005), direction selectivity of single cortical units may or may not contribute to this discrimination. Difference in the kinematics of the contact of multiple whiskers along with the ego head motions could provide the information about the orientation of an object. Thus, the extent to which rats can extract the direction of a vibro-tactile stimulus using only one whisker is not yet known. Recent findings revealed that mice learned to detect optical microstimulation of a sparse group of supra-granular neurons in SI (Huber et al., 2007), as well as the difference between temporal patterns of electrical micro-stimulation (Yang and Zador, 2012). As vibrations with different orientation elicit responses in distinct populations of cortical neurons, the rat might be able to use that population information to decode orientation. A key test is to see if rats generalize the learned behavior when stimulus is presented to another whisker.

\subsection{Linking Cortical Function and Behavioral Context}

A given sensory stimulus may convey different meanings depending on the time and context of its occurrence, requiring the organism to take different courses of action. Sensory processing also changes with behavioral context: for example, high amplitude oscillations (known as mu rhythm) are observed in sensorimotor areas when subjects are immobile with focused attention (Kuhlman, 1978; Rougeul et al., 1979; Bouyer et al., 1981). Similar oscillations were observed in membrane potentials recorded from layer II/III neurons of mice SI in receptive mode (Crochet and Petersen, 2006). In generative mode during free whisking, however, the synchronous fluctuations were suppressed and decorrelated (Crochet and Petersen, 2006; Poulet and Petersen, 2008; Gentet et al., 2010, 2012). Beyond the spontaneous oscillations, sensory stimuli delivered to whiskers of awake rats and mice evoked a smaller response amplitude in the generative mode compared to receptive mode (CastroAlamancos, 2004; Ferezou et al., 2006, 2007). Similar response suppression during active behavior was observed in rat auditory cortex (Otazu et al., 2009), while a response enhancement was observed in visual cortex (Niell and Stryker, 2010; Keller et al., 2012). Functional interaction between sensory and motor areas at different behavioral modes (Matyas et al., 2010; Niell and Stryker, 2010; Keller et al., 2012) and thalamocortical synaptic depression (Castro-Alamancos and Oldford, 2002; Otazu et al., 2009; Poulet et al., 2012) could account for changes in the sensorydriven response dynamics during active behavior. Grion et al. (2016) reported increased hippocampal theta band oscillations during texture discrimination task compared to a memory task in rats. This was accompanied by an enhanced phaselock synchronization between whisking rhythm, SI neuronal spiking activity and hippocampal theta oscillation. Future paired recordings from primary somatosensory cortex and primary motor cortex or sensorimotor thalamic areas in awake rodents are required to understand the functional role and interaction of these areas in sensory processing and sensation.

Cortical neurons process information on a background of ongoing activity with distinct spatiotemporal dynamics forming various cortical states. During wakefulness, cortical state changes constantly in relation to behavioral context, attentional level or general motor activity. A common observation in awake rodents is the rapid change in spontaneous cortical activity from high-amplitude, low-frequency fluctuations referred to as synchronized state (e.g., when animals are quiet), to faster and smaller fluctuations, referred to as desynchronized state (e.g., when animals are active). Fazlali et al. (2016) recently showed this re-organization of the activity of cortical networks strongly affects sensory processing. In the desynchronized state, cortical neurons showed lower stimulus detection threshold, higher response fidelity, and shorter response latency with a prominent enhanced late response. Interestingly, changes in the activity of a small population of locus coeruleus (LC) neurons preceded and predicted the changes in the cortical state: the cross-correlation of the LC firing profile with the cortical state was maximal at an average lag of $-1.2 \mathrm{~s}$.

\subsection{Link to Perception}

It is not clear how and where in neocortex the perception of the tactile information emerges. However, a prime candidate for perceptual judgments and navigation based on tactile information is the prefrontal cortex (PFC). Somatosensory cortex projects into the dorsal part of medial prefrontal cortex (mPFC) (Conde et al., 1995) — homolog of primate dorsolateral prefrontal cortex. There are several lines of evidence indicating that in rats, $\mathrm{mPFC}$ and in particular its dorsal bank is involved in memory and delayed tasks (Larsen and Divac, 1978; Thomas and Brito, 1980; Eichenbaum et al., 1983; Wolf et al., 1987; Brabander et al., 1991; Granon et al., 1994; Verma and Moghaddam, 1996, but see de Bruin et al., 1994; Sánchez-Santed et al., 1997; Ragozzino et al., 1998). Prefrontal cortex also projects to hippocampus both directly and indirectly through lateral entorhinal cortex. The entorhinal cortex gates sensory information to hippocampus and its lesioning impairs spatial representation (Brun et al., 2008). 
Moreover, population dynamics of place-selective grid cells in the medial entorhinal cortex predict adaptive hippocampal remapping (Fyhn et al., 2007). Somatosensory cortex projects to the lateral entorhinal cortex through indirect projections via perirhinal cortex and also via weaker direct projections. This potentially forms an additional pathway of vibrissal information to hippocampus.

\section{CONCLUDING REMARKS}

Recent years have witnessed a revitalization of interest in rodent models not only in systems neuroscience, but also in the whole body of neuroscience research. This revitalization is partly due to availability of an increasingly powerful array of experimental approaches from optogenetics and two-photon imaging to whole-cell and intracellular electrophysiology and labeling that are challenging to apply to their full potential in primates. Availability of a broad range of genetically modified mouse lines offer scientists the tools to precisely target neuronal circuits and specific cell-types to study their function. The flat surface of the cortex in rodents without sulci and gyri along with its relatively small size is an asset for application of the stateof-the-art battery of techniques in observation and perturbation of neuronal activity. While the rodent somatosensory cortex is probably the most studied system in the literature, providing an immense amount of data from genome expression to cell types and neuronal circuitry, yet there is a huge gap in our understanding and knowledge about how this system functions. Filling this gap requires a comprehensive and coordinated drive from multiple disciplines including but not limited to cellular, systems, computational, behavioral and cognitive neuroscience.

The somatosensory system is an expert system in rodents. This system comprises one of the major channels through which rodents as nocturnal animals collect information about their surrounding environment, making this system an ideal model system to understand the neuronal computations

\section{REFERENCES}

Adelson, E. H., and Bergen, J. R. (1985). Spatiotemporal energy models for the perception of motion. J. Opt. Soc. Am. A 2, 284-299.

Adibi, M., and Arabzadeh, E. (2011). A comparison of neuronal and behavioral detection and discrimination performances in rat whisker system. $J$. Neurophysiol. 105:356. doi: 10.1152/jn.00794.2010

Adibi, M., Clifford, C. W., and Arabzadeh, E. (2013a). Informational basis of sensory adaptation: entropy and single-spike efficiency in rat barrel cortex. J. Neurosci. 33, 14921-14926. doi: 10.1523/JNEUROSCI.131313.2013

Adibi, M., Diamond, M. E., and Arabzadeh, E. (2012). Behavioral study of whiskermediated vibration sensation in rats. Proc. Natl. Acad. Sci. U.S.A. 109, 971-976. doi: 10.1073/pnas.1116726109

Adibi, M., McDonald, J. S., Clifford, C. W., and Arabzadeh, E. (2013b). Adaptation improves neural coding efficiency despite increasing correlations in variability. J. Neurosci. 33, 2108-2120. doi: 10.1523/JNEUROSCI.3449-12.2013

Adibi, M., McDonald, J. S., Clifford, C. W., and Arabzadeh, E. (2014). Population decoding in rat barrel cortex: optimizing the linear readout of correlated population responses. PLoS Comput. Biol. 10:e1003415. doi: 10.1371/journal.pcbi.1003415 and their underlying cellular and neuronal mechanisms in information processing and decision making. Recent studies reveal complex cognitive functions in rodent somatosensation previously reported in humans and primates such as evidence accumulation for optimal decision making and forming abstract concepts of noisy stimulation patterns (Fassihi et al., 2014; Zuo and Diamond, 2019b). Yet, further behavioral studies are required to unveil the cognitive abilities in rodents. The role of different connections and areas in this system (see Figure 1) such as vSII, vMI, TRN, ZI, and SC in different contextual and behavioral conditions is yet to be understood. Within cortical areas, the effect of different laminae and a variety of cell types (Narayanan et al., 2017) within this architecture on different aspects of sensory processing and behavior is not clear, and requires further investigation in future studies.

\section{AUTHOR CONTRIBUTIONS}

MA drafted and wrote the manuscript.

\section{FUNDING}

MA is supported by an CJ Martin Early Career Fellowship (GNT1110421) from the Australian National Health and Medical Research Council (NMHRC).

\section{ACKNOWLEDGMENTS}

The author would like to thank the members of the Tactile Perception and Learning Lab, SISSA, Italy and the Neural Coding Lab, JCSMR, ANU, Australia, particularly Mathew Diamond and Ehsan Arabzadeh for their comments. The author would like to express gratitude to all people who supported this work at the University of New South Wales and the University of Padova. The author also would like to thank Nelly Redolfi for the inspiration and support to complete this work.
Agmon, A., and Connors, B. W. (1991). Thalamocortical responses of mouse somatosensory (barrel) cortex in vitro. Neuroscience 41, 365-379. doi: 10.1016/0306-4522(91)90333-J

Agmon, A., Yang, L. T., Jones, E. G., and O’Dowd, D. K. (1995). Topological precision in the thalamic projection to neonatal mouse barrel cortex. J. Neurosci. 15, 549-561. doi: 10.1523/JNEUROSCI.15-01-00549.1995

Ahissar, E., and Knutsen, P. (2008). Object localization with whiskers. Biol. Cybern. 98, 449-458. doi: 10.1007/s00422-008-0214-4

Ahissar, E., Sosnik, R., and Haidarliu, S. (2000). Transformation from temporal to rate coding in a somatosensory thalamocortical pathway. Nature 406, 302-306. doi: $10.1038 / 35018568$

Ahissar, E., and Staiger, J. (2010). S1 laminar specialization. Scholarpedia 5:7457. doi: $10.4249 /$ scholarpedia.7457

Alloway, K. D., Hoffer, Z. S., and Hoover, J. E. (2003). Quantitative comparisons of corticothalamic topography within the ventrobasal complex and the posterior nucleus of the rodent thalamus. Brain Res. 968, 54-68. doi: 10.1016/S0006-8993(02)04265-8

Alloway, K. D., Lou, L., Nwabueze-Ogbo, F., and Chakrabarti, S. (2006). Topography of cortical projections to the dorsolateral neostriatum in rats: multiple overlapping sensorimotor pathways. J. Compar. Neurol. 499, 33-48. doi: $10.1002 /$ cne.21039 
Aloimonos, J. (1990). "Purposive and qualitative active vision," in 10th International Conference on Pattern Recognition, Vol. 1, (Atlantic City, NJ), 346-360. doi: 10.1109/ICPR.1990.118128

Aloimonos, J., Weiss, I., and Bandyopadhyay, A. (1988). Active vision. Int. J. Comput. Vis. 1, 333-356. doi: 10.1007/BF00133571

Andermann, M. L., and Moore, C. I. (2006). A somatotopic map of vibrissa motion direction within a barrel column. Nat. Neurosci. 9, 543-551. doi: 10.1038/nn1671

Arabzadeh, E., Panzeri, S., and Diamond, M. E. (2004). Whisker vibration information carried by rat barrel cortex neurons. J. Neurosci. 24, 6011-6020. doi: 10.1523/JNEUROSCI.1389-04.2004

Arabzadeh, E., Petersen, R. S., and Diamond, M. E. (2003). Encoding of whisker vibration by rat barrel cortex neurons: implications for texture discrimination. J. Neurosci. 23, 9146-9154. doi: 10.1523/JNEUROSCI.23-27-09146.2003

Arabzadeh, E., Zorzin, E., and Diamond, M. E. (2005). Neuronal encoding of texture in the whisker sensory pathway. PLoS Biol. 3:e17. doi: 10.1371/journal.pbio.0030017

Armstrong-James, M., Callahan, C. A., and Friedman, M. A. (1991). Thalamocortical processing of vibrissal information in the rat. I. Intracortical origins of surround but not centre-receptive fields of layer IV neurones in the rat S1 barrel field cortex. J. Compar. Neurol. 303, 193-210. doi: 10.1002/cne.903030203

Armstrong-James, M., and Fox, K. (1987). Spatiotemporal convergence and divergence in the rat S1 "barrel" cortex. J. Compar. Neurol. 263, 265-281. doi: $10.1002 / \mathrm{cne} .902630209$

Armstrong-James, M., Fox, K., and Das-Gupta, A. (1992). Flow of excitation within rat barrel cortex on striking a single vibrissa. J. Neurophysiol. 68, 1345-1358. doi: 10.1152/jn.1992.68.4.1345

Arvidsson, J. (1982). Somatotopic organization of vibrissae afferents in the trigeminal sensorynuclei of the rat studied by transganglionic transport of HRP. J. Compar. Neurol. 211, 84-92. doi: 10.1002/cne.902110108

Barbaresi, P., Spreafico, R., Frassoni, C., and Rustioni, A. (1986). GABAergic neurons are present in the dorsal column nuclei but not in the ventroposterior complex of rats. Brain Res. 382:305. doi: 10.1016/0006-8993(86)91340-5

Bari, B. A., Ollerenshaw, D. R., Millard, D. C., Wang, Q., and Stanley, G. B. (2013). Behavioral and electrophysiological effects of cortical microstimulation parameters. PLoS ONE 8:e82170. doi: 10.1371/journal.pone.0082170

Barlow, H. B., and Levick, W. R. (1969). Three factors limiting the reliable detection of light by retinal ganglion cells of the cat. J. Physiol. 200:1. doi: 10.1113/jphysiol.1969.sp008679

Barlow, H. B., Levick, W. R., and Yoon, M. (1971). Responses to single quanta of light in retinal ganglion cells of the cat. Vis. Res. 11(Suppl. 3), 87-101. doi: 10.1016/0042-6989(71)90033-2

Barthó, P., Freund, T., and Acsády, L. (2002). Selective GABAergic innervation of thalamic nuclei from zona incerta. Eur. J. Neurosci. 16, 999-1014. doi: 10.1046/j.1460-9568.2002.02157.x

Barthó, P., Slézia, A., Varga, V., Bokor, H., Pinault, D., Buzsáki, G., et al. (2007). Cortical control of zona incerta. J. Neurosci. 27, 1670-1681. doi: 10.1523/JNEUROSCI.3768-06.2007

Bates, C. A., and Killackey, H. P. (1985). The organization of the neonatal rat's brainstem trigeminal complex and its role in the formation of central trigeminal patterns. J. Compar. Neurol. 240, 265-287. doi: 10.1002/cne.902400305

Belford, G. R., and Killackey, H. P. (1979). Vibrissae representation in subcortical trigeminal centers of the neonatal rat. J. Compar. Neurol. 183, 305-321. doi: $10.1002 / \mathrm{cne} .901830207$

Bellavance, M.-A., Demers, M., and Deschênes, M. (2010). Feedforward inhibition determines the angular tuning of vibrissal responses in the principal trigeminal nucleus. J. Neurosci. 30, 1057-1063. doi: 10.1523/JNEUROSCI.4805-09.2010

Benison, A. M., Rector, D. M., and Barth, D. S. (2007). Hemispheric mapping of secondary somatosensory cortex in the rat. J. Neurophysiol. 97, 200-207. doi: 10.1152/jn.00673.2006

Bennett-Clarke, C. A., Chiaia, N. L., Jacquin, M. F., and Rhoades, R. W. (1992). Parvalbumin and calbindin immunocytochemistry reveal functionally distinct cell groups and vibrissa-related patterns in the trigeminal brainstem complex of the adult rat. J. Compar. Neurol. 320, 323-338. doi: 10.1002/cne.903200305

Berg, R. W., and Kleinfeld, D. (2003). Rhythmic whisking by rat: Retraction as well as protraction of the vibrissae is under active muscular control. J. Neurophysiol. 89, 104-117. doi: 10.1152/jn.00600.2002
Bernardo, K. L., McCasland, J. S., and Woolsey, T. A. (1990a). Local axonal trajectories in mouse barrel cortex. Exp. Brain Res. 82, 247-253. doi: 10.1007/BF00231244

Bernardo, K. L., McCasland, J. S., Woolsey, T. A., and Strominger, R. N. (1990b). Local intra- and interlaminar connections in mouse barrel cortex. J. Compar. Neurol. 291, 231-255. doi: 10.1002/cne.902910207

Bernardo, K. L., and Woolsey, T. A. (1987). Axonal trajectories between mouse somatosensory thalamus and cortex. J. Compar. Neurol. 258, 542-564. doi: $10.1002 /$ cne. 902580406

Blasdel, G. G., and Salama, G. (1986). Voltage-sensitive dyes reveal a modular organization in monkey striate cortex. Nature 321, 579-585. doi: $10.1038 / 321579 \mathrm{a} 0$

Bokor, H., Frère, S. G., Eyre, M. D., Slézia, A., Ulbert, I., Lüthi, A., et al. (2005) Selective gabaergic control of higher-order thalamic relays. Neuron 45, 929 940. doi: 10.1016/j.neuron.2005.01.048

Bonhoeffer, T., and Grinvald, A. (1991). Iso-orientation domains in cat visual cortex are arranged in pinwheel-like patterns. Nature 353, 429-431. doi: $10.1038 / 353429 \mathrm{a} 0$

Bourassa, J., Pinault, D., and Deschênes, M. (1995). Corticothalamic projections from the cortical barrel field to the somatosensory thalamus in rats: a singlefibre study using biocytin as an anterograde tracer. Eur. J. Neurosci. 7, 19-30. doi: 10.1111/j.1460-9568.1995.tb01016.x

Bouyer, J. J., Montaron, M. F., and Rougeul, A. (1981). Fast fronto-parietal rhythms during combined focused attentive behaviour and immobility in cat: cortical and thalamic localizations. Electroencephalogr. Clin. Neurophysiol. 51, 244-252. doi: 10.1016/0013-4694(81)90138-3

Brecht, M. (2007). Barrel cortex and whisker-mediated behaviors. Curr. Opin. Neurobiol. 17, 408-416. doi: 10.1016/j.conb.2007.07.008

Brecht, M., Preilowski, B., and Merzenich, M. M. (1997). Functional architecture of the mystacial vibrissae. Behav. Brain Res. 84, 81-97. doi: 10.1016/S0166-4328(97)83328-1

Brecht, M., Roth, A., and Sakmann, B. (2003). Dynamic receptive fields of reconstructed pyramidal cells in layers 3 and 2 of rat somatosensory barrel cortex. J. Physiol. 553, 243-265. doi: 10.1113/jphysiol.2003.044222

Brecht, M., and Sakmann, B. (2002). Dynamic representation of whisker deflection by synaptic potentials in spiny stellate and pyramidal cells in the barrels and septa of layer 4 rat somatosensory cortex. J. Physiol. 543, 49-70. doi: 10.1113/jphysiol.2002.018465

Bruce, L. L., McHaffie, J. G., and Stein, B. E. (1987). The organization of trigeminotectal and trigeminothalamic neurons in rodents: a doublelabeling study with fluorescent dyes. J. Compar. Neurol. 262, 315-330. doi: $10.1002 / \mathrm{cne} .902620302$

Brun, V. H., Leutgeb, S. Q., Wu, H., Schwarcz, R., Witter, M. P., Moser, E. I., et al. (2008). Impaired spatial representation in CA1 after lesion of direct input from entorhinal cortex. Neuron 57, 290-302. doi: 10.1016/j.neuron.2007.11.034

Bruno, R. M., Khatri, V., Land, P. W., and Simons, D. J. (2003). Thalamocortical angular tuning domains within individual barrels of rat somatosensory cortex. J. Neurosci. 23, 9565-9574. doi: 10.1523/JNEUROSCI.23-29-09565.2003

Bruno, R. M., and Simons, D. J. (2002). Feedforward mechanisms of excitatory and inhibitory cortical receptive fields. J. Neurosci. 22, 10966-10975. doi: 10.1523/JNEUROSCI.22-24-10966.2002

Bureau, I., von Saint Paul, F., and Svoboda, K. (2006). Interdigitated paralemniscal and lemniscal pathways in the mouse barrel cortex. PLoS Biol. 4:e382. doi: 10.1371/journal.pbio.0040382

Buzsaki, G. (2009). Rhythms of the Brain. Oxford: Oxford University Press.

Cao, Y., Roy, S., Sachdev, R. N., and Heck, D. H. (2012). Dynamic correlation between whisking and breathing rhythms in mice. J. Neurosci. 32, 1653-1659. doi: 10.1523/JNEUROSCI.4395-11.2012

Carvell, G. E., and Simons, D. J. (1986). Somatotopic organization of the second somatosensory area (SII) in the cerebral cortex of the mouse. Somatosens. Mot. Res. 3, 213-237. doi: 10.3109/07367228609144585

Carvell, G. E., and Simons, D. J. (1987). Thalamic and corticocortical connections of the second somatic sensory area of the mouse. J. Compar. Neurol. 265, 409-427. doi: 10.1002/cne.902650309

Carvell, G. E., and Simons, D. J. (1990). Biometric analyses of vibrissal tactile discrimination in the rat. J. Neurosci. 10, 2638-2648. doi: 10.1523/JNEUROSCI.10-08-02638.1990 
Carvell, G. E., and Simons, D. J. (1995). Task- and subject-related differences in sensorimotor behavior during active touch. Somatosens. Mot. Res. 12, 1-9. doi: 10.3109/08990229509063138

Carvell, G. E., Simons, D. J., Lichtenstein, S. H., and Bryant, P. (1991). Electromyographic activity of mystacial pad musculature during whisking behavior in the rat. Somatosens. Mot. Res. 8, 159-164. doi: $10.3109 / 08990229109144740$

Castro-Alamancos, M. A. (2004). Absence of rapid sensory adaptation in neocortex during information processing states. Neuron 41, 455-464. doi: 10.1016/S0896-6273(03)00853-5

Castro-Alamancos, M. A., and Oldford, E. (2002). Cortical sensory suppression during arousal is due to the activity-dependent depression of thalamocortical synapses. J. Physiol. 541, 319-331. doi: 10.1113/jphysiol.2002.016857

Celikel, T., and Sakmann, B. (2007). Sensory integration across space and in time for decision making in the somatosensory system of rodents. Proc. Natl. Acad. Sci. U.S.A. 104, 1395-1400. doi: 10.1073/pnas.0610267104

Chakrabarti, S., and Alloway, K. (2006). Differential origin of projections from si barrel cortex to the whisker representations in SII and MI. J. Compar. Neurol. 498:624. doi: 10.1002/cne.21052

Chen, J. L., Carta, S., Soldado-Magraner, J., Schneider, B. L., and Helmchen, F. (2013). Behaviour-dependent recruitment of long-range projection neurons in somatosensory cortex. Nature 499:336. doi: 10.1038/nature12236

Chiaia, N. L., Bennett-Clarke, C. A., and Rhoades, R. W. (1991). Effects of cortical and thalamic lesions upon primary afferent terminations, distributions of projection neurons, and the cytochrome oxidase pattern in the trigeminal brainstem complex. J. Compar. Neurol. 303, 600-616. doi: $10.1002 / \mathrm{cne} .903030407$

Chmielowska, J., Carvell, G. E., and Simons, D. J. (1989). Spatial organization of thalamocortical and corticothalamic projection systems in the rat smi barrel cortex. J. Compar. Neurol. 285, 325-338. doi: 10.1002/cne.902850304

Churchland, M. M., Byron, M. M., Cunningham, J. P., Sugrue, L. P., Cohen, M. R., Corrado, G. S., et al. (2010). Stimulus onset quenches neural variability: a widespread cortical phenomenon. Nat. Neurosci. 13, 369-378. doi: 10.1038/nn.2501

Churchland, M. M., Byron, M. M., Ryu, S. I., Santhanam, G., and Shenoy, K. V. (2006). Neural variability in premotor cortex provides a signature of motor preparation. J. Neurosci. 26, 3697-3712. doi: 10.1523/JNEUROSCI.3762-05.2006

Cohen, M. R., and Newsome, W. T. (2009). Estimates of the contribution of single neurons to perception depend on timescale and noise correlation. J. Neurosci. 29:6635. doi: 10.1523/JNEUROSCI.5179-08.2009

Conde, F., Mairelepoivre, E., Audinat, E., and Crepel, F. (1995). Afferent connections of the medial frontal-cortex of the rat. 2. Cortical and subcortical afferents. J. Compar. Neurol. 352, 567-593. doi: 10.1002/cne.903520407

Constantinople, C. M., and Bruno, R. M. (2013). Deep cortical layers are activated directly by thalamus. Science 340, 1591-1594. doi: 10.1126/science.1236425

Crandall, S. R., Patrick, S. L., Cruikshank, S. J., and Connors, B. W. (2017). Infrabarrels are layer 6 circuit modules in the barrel cortex that link long-range inputs and outputs. Cell Rep. 21, 3065-3078. doi: 10.1016/j.celrep.2017.11.049

Crick, F. (1984). Function of the thalamic reticular complex: the searchlight hypothesis. Proc. Natl. Acad. Sci. U.S.A. 81, 4586-4590. doi: $10.1073 /$ pnas.81.14.4586

Crochet, S., and Petersen, C. C. (2006). Correlating whisker behavior with membrane potential in barrel cortex of awake mice. Nat. Neurosci. 9, 608-610. doi: $10.1038 / \mathrm{nn} 1690$

Crochet, S., Poulet, J. F., Kremer, Y., and Petersen, C. C. (2011). Synaptic mechanisms underlying sparse coding of active touch. Neuron 69, 1160-1175. doi: 10.1016/j.neuron.2011.02.022

Curtis, J. C., and Kleinfeld, D. (2009). Phase-to-rate transformations encode touch in cortical neurons of a scanning sensorimotor system. Nat. Neurosci. 12, 492-501. doi: 10.1038/nn.2283

de Brabander, J. M., de Bruin, J. P., and van Eden, C. G. (1991). Comparison of the effects of neonatal and adult medial prefrontal cortex lesions on food hoarding and spatial delayed alternation. Behav. Brain Res. 42, 67-75. doi: 10.1016/S0166-4328(05)80041-5

de Bruin, J., Sánchez-Santed, F., Heinsbroek, R., Donker, A., and Postmes, P. (1994). A behavioural analysis of rats with damage to the medial prefrontal cortex using the morris water maze: Evidence for behavioural flexibility, but not for impaired spatial navigation. Brain Res. 652, 323-333. doi: 10.1016/0006-8993(94)90243-7

de Lafuente, V., and Romo, R. (2006). Neural correlate of subjective sensory experience gradually builds up across cortical areas. Proc. Natl. Acad. Sci. U.S.A. 103:14266. doi: 10.1073/pnas.0605826103

Deschênes, M., Moore, J., and Kleinfeld, D. (2012). Sniffing and whisking in rodents. Curr. Opin. Neurobiol. 22, 243-250. doi: 10.1016/j.conb.2011.11.013

Deschênes, M., Takatoh, J., Kurnikova, A., Moore, J. D., Demers, M., Elbaz, M., et al. (2016). Inhibition, not excitation, drives rhythmic whisking. Neuron 90, 374-387. doi: 10.1016/j.neuron.2016.03.007

Deschênes, M., Veinante, P., and Zhang, Z.-W. (1998). The organization of corticothalamic projections: reciprocity versus parity. Brain Res. Rev. 28, 286-308. doi: 10.1016/S0165-0173(98)00017-4

Desilets-Roy, B., Varga, C., Lavallée, P., and Deschênes, M. (2002). Substrate for cross-talk inhibition between thalamic barreloids. J. Neurosci. 22, RC218-RC218. doi: 10.1523/JNEUROSCI.22-09-j0002.2002

Di, S., Baumgartner, C., and Barth, D. S. (1990). Laminar analysis of extracellular field potentials in rat vibrissa/barrel cortex. J. Neurophysiol. 63, 832-840. doi: 10.1152/jn.1990.63.4.832

Diamond, M. E. (1995). "Somatosensory thalamus of the rat," in Cerebral Cortex: The Barrel Cortex of Rodents, Vol. 11, eds E. G. Jones and I. T. Diamond (New York, NY: Plenum Press), 189-219.

Diamond, M. E., and Arabzadeh, E. (2013). Whisker sensory system: from receptor to decision. Prog. Neurobiol. 103, 28-40. doi: 10.1016/j.pneurobio.2012.05.013

Diamond, M. E., Armstrong-James, M., and Ebner, F. F. (1992). Somatic sensory responses in the rostral sector of the posterior group (POM) and in the ventral posterior medial nucleus (VPM) of the rat thalamus. J. Compar. Neurol. 318, 462-476. doi: 10.1002/cne.903180410

Diamond, M. E., Von Heimendahl, M., and Arabzadeh, E. (2008). Whisker-mediated texture discrimination. PLoS Biol. 6:e220. doi: 10.1371/journal.pbio.0060220

Dörfl, J. (1982). The musculature of the mystacial vibrissae of the white mouse. $J$. Anat. 135(Pt 1):147.

Dörfl, J. (1985). The innervation of the mystacial region of the white mouse: a topographical study. J. Anat. 142, 173-184.

Durham, D., and Woolsey, T. A. (1984). Effects of neonatal whisker lesions on mouse central trigeminal pathways. J. Compar. Neurol. 223, 424-447. doi: $10.1002 /$ cne. 902230308

Dykes, R. (1975). Afferent fibers from mystacial vibrissae of cats and seals. J. Neurophysiol. 38, 650-662. doi: 10.1152/jn.1975.38.3.650

Ebara, S., Kumamoto, K., Matsuura, T., Mazurkiewicz, J. E., and Rice, F. L. (2002) Similarities and differences in the innervation of mystacial vibrissal folliclesinus complexes in the rat and cat: a confocal microscopic study. J. Compar. Neurol. 449, 103-119. doi: 10.1002/cne.10277

Ego-Stengel, V., Mello E Souza, T., Jacob, V., and Shulz, D. E. (2005). Spatiotemporal characteristics of neuronal sensory integration in the barrel cortex of the rat. J. Neurophysiol. 93, 1450-1467. doi: 10.1152/jn.00912.2004

Eichenbaum, H., Clegg, R. A., and Feeley, A. (1983). Reexamination of functional subdivisions of the rodent prefrontal cortex. Exp. Neurol. 79, 434-451. doi: 10.1016/0014-4886(83)90224-8

Emmers, R. (1965). Organization of the first and the second somesthetic regions (SI and SII) in the rat thalamus. J. Compar. Neurol. 124, 215-227. doi: $10.1002 / \mathrm{cne} .901240207$

Erzurumlu, R. S., and Killackey, H. P. (1980). Diencephalic projections of the subnucleus interpolaris of the brainstem trigeminal complex in the rat. Neuroscience 5:1891. doi: 10.1016/0306-4522(80)90037-8

Estebanez, L., El Boustani, S., Destexhe, A., and Shulz, D. E. (2012). Correlated input reveals coexisting coding schemes in a sensory cortex. Nat. Neurosci. 15, 1691-1699. doi: 10.1038/nn.3258

Fanselow, E. E., and Nicolelis, M. A. (1999). Behavioral modulation of tactile responses in the rat somatosensory system. J. Neurosci. 19, 7603-7616. doi: 10.1523/JNEUROSCI.19-17-07603.1999

Fassihi, A., Akrami, A., Esmaeili, V., and Diamond, M. E. (2014). Tactile perception and working memory in rats and humans. Proc. Natl. Acad. Sci. U.S.A. 111, 2331-2336. doi: 10.1073/pnas.1315171111

Fassihi, A., Akrami, A., Pulecchi, F., Schönfelder, V., and Diamond, M. E. (2017). Transformation of perception from sensory to motor cortex. Curr. Biol. 27, 1585-1596. doi: 10.1016/j.cub.2017.05.011 
Fazlali, Z., Ranjbar-Slamloo, Y., Adibi, M., and Arabzadeh, E. (2016). Correlation between cortical state and locus coeruleus activity: implications for sensory coding in rat barrel cortex. Front. Neural Circuits 10:14. doi: 10.3389/fncir.2016.00014

Fee, M. S., Mitra, P. P., and Kleinfeld, D. (1997). Central versus peripheral determinants of patterned spike activity in rat vibrissa cortex during whisking. J. Neurophysiol. 78, 1144-1149. doi: 10.1152/jn.1997.78.2.1144

Feldman, J. L., and Kam, K. (2015). Facing the challenge of mammalian neural microcircuits: taking a few breaths may help. J. Physiol. 593, 3-23. doi: 10.1113/jphysiol.2014.277632

Feldmeyer, D. (2012). Excitatory neuronal connectivity in the barrel cortex. Front. Neuroanat. 6:24. doi: 10.3389/fnana.2012.00024

Feldmeyer, D., Egger, V., Lübke, J., and Sakmann, B. (1999). Reliable synaptic connections between pairs of excitatory layer 4 neurones within a single 'barrel' of developing rat somatosensory cortex. J. Physiol. 521, 169-190. doi: 10.1111/j.1469-7793.1999.00169.x

Feldmeyer, D., Roth, A., and Sakmann, B. (2005). Monosynaptic connections between pairs of spiny stellate cells in layer 4 and pyramidal cells in layer $5 \mathrm{a}$ indicate that lemniscal and paralemniscal afferent pathways converge in the infragranular somatosensory cortex. J. Neurosci. 25, 3423-3431. doi: 10.1523/JNEUROSCI.5227-04.2005

Ferezou, I., Bolea, S., and Petersen, C. C. (2006). Visualizing the cortical representation of whisker touch: voltage-sensitive dye imaging in freely moving mice. Neuron 50, 617-629. doi: 10.1016/j.neuron.2006.03.043

Ferezou, I., Haiss, F., Gentet, L. J., Aronoff, R., Weber, B., and Petersen, C. C. (2007). Spatiotemporal dynamics of cortical sensorimotor integration in behaving mice. Neuron 56, 907-923. doi: 10.1016/j.neuron.2007.10.007

Fernández, L. M., Vantomme, G., Osorio-Forero, A., Cardis, R., Béard, E., and Lüthi, A. (2018b). Thalamic reticular control of local sleep in mouse sensory cortex. eLife 7:e39111. doi: 10.7554/eLife.39111

Fitzgerald, O. (1940). Discharges from the sensory organs of the cat's vibrissae and the modification in their activity by ions. J. Physiol. 98, 163-178. doi: 10.1113/jphysiol.1940.sp003841

Friedberg, M. H., Lee, S. M., and Ebner, F. F. (1999). Modulation of receptive field properties of thalamic somatosensory neurons by the depth of anesthesia. J. Neurophysiol. 81, 2243-2252. doi: 10.1152/jn.1999.81.5.2243

Fuentealba, P., and Steriade, M. (2005). The reticular nucleus revisited: intrinsic and network properties of a thalamic pacemaker. Prog. Neurobiol. 75, 125-141. doi: 10.1016/j.pneurobio.2005.01.002

Furuta, T., Kaneko, T., and Deschenes, M. (2009). Septal neurons in barrel cortex derive their receptive field input from the lemniscal pathway. J. Neurosci. 29, 4089-4095. doi: 10.1523/JNEUROSCI.5393-08.2009

Furuta, T., Nakamura, K., and Deschênes, M. (2006). Angular tuning bias of vibrissa-responsive cells in the paralemniscal pathway. J. Neurosci. 26, 1054810557. doi: 10.1523/JNEUROSCI.1746-06.2006

Fyhn, M., Hafting, T., Treves, A., Moser, M. B., and Moser, E. I. (2007). Hippocampal remapping and grid realignment in entorhinal cortex. Nature 446, 190-194. doi: 10.1038/nature05601

Ganguly, K., and Kleinfeld, D. (2004). Goal-directed whisking increases phaselocking between vibrissa movement and electrical activity in primary sensory cortex in rat. Proc. Natl. Acad. Sci. U.S.A. 101, 12348-12353. doi: 10.1073/pnas.0308470101

Gentet, L. J., Avermann, M., Matyas, F., Staiger, J. F., and Petersen, C. C. H. (2010). Membrane potential dynamics of GABAergic neurons in the barrel cortex of behaving mice. Neuron 65, 422-435. doi: 10.1016/j.neuron.2010. 01.006

Gentet, L. J., Kremer, Y., Taniguchi, H., Huang, Z. J., Staiger, J. F., and Petersen, C. C. H. (2012). Unique functional properties of somatostatin-expressing GABAergic neurons in mouse barrel cortex. Nat. Neurosci. 15, 607-612. doi: $10.1038 / \mathrm{nn} .3051$

Gerdjikov, T. V., Bergner, C. G., Stüttgen, M. C., Waiblinger, C., and Schwarz, C. (2010). Discrimination of vibrotactile stimuli in the rat whisker system: behavior and neurometrics. Neuron 65, 530-540. doi: 10.1016/j.neuron.2010.02.007

Ghazanfar, A. A., and Nicolelis, M. A. (1997). Nonlinear processing of tactile information in the thalamocortical loop. J. Neurophysiol. 78, 506-510. doi: 10.1152/jn.1997.78.1.506
Ghazanfar, A. A., and Nicolelis, M. A. (1999). Spatiotemporal properties of layer V neurons of the rat primary somatosensory cortex. Cereb. Cortex 9, 348-361. doi: $10.1093 /$ cercor/9.4.348

Gibson, J. (1962). Observations on active touch. Psychol. Rev. 69:477. doi: $10.1037 / \mathrm{h} 0046962$

Gibson, J. M., and Welker, W. I. (1983a). Quantitative studies of stimulus coding in first-order vibrissa afferents of rats. 1. receptive field properties and threshold distributions. Somatosens. Mot. Res. 1, 51-67. doi: 10.3109/07367228309144540

Gibson, J. M., and Welker, W. I. (1983b). Quantitative studies of stimulus coding in first-order vibrissa afferents of rats. 2. Adaptation and coding of stimulus parameters. Somatosens. Mot. Res. 1, 95-117. doi: 10.3109/07367228309144543

Gottschaldt, K. M., Iggo, A., and Young, D. W. (1973). Functional characteristics of mechanoreceptors in sinus hair follicles of the cat. J. Physiol. 235, 287-315. doi: 10.1113/jphysiol.1973.sp010388

Granon, S., Vidal, C., Thinus-Blanc, C., Changeux, J. P., and Poucet, B. (1994). Working memory, response selection, and effortful processing in rats with medial prefrontal lesions. Behav. Neurosci. 108:883. doi: 10.1037/0735-7044.108.5.883

Grant, R. A., Mitchinson, B., Fox, C. W., and Prescott, T. J. (2009). Active touch sensing in the rat: anticipatory and regulatory control of whisker movements during surface exploration. J. Neurophysiol. 101:862. doi: 10.1152/jn.90783.2008

Grinvald, A., Lieke, E., Frostig, R. D., Gilbert, C. D., and Wiesel, T. N. (1986). Functional architecture of cortex revealed by optical imaging of intrinsic signals. Nature 324, 361-364. doi: 10.1038/324361a0

Grion, N., Akrami, A., Zuo, Y., Stella, F., and Diamond, M. E. (2016). Coherence between rat sensorimotor system and hippocampus is enhanced during tactile discrimination. PLoS Biol. 14:e1002384. doi: 10.1371/journal.pbio.1002384

Guić-Robles, E., Jenkins, W. M., and Bravo, H. (1992). Vibrissal roughness discrimination is barrel cortex-dependent. Behav. Brain Res. 48, 145-152. doi: 10.1016/S0166-4328(05)80150-0

Guic-Robles, E., Valdivieso, C., and Guajardo, G. (1989). Rats can learn a roughness discrimination using only their vibrissal system. Behav. Brain Res. 31, 285-289. doi: 10.1016/0166-4328(89)90011-9

Guo, Z. V., Hires, S. A., Li, N., O’Connor, D. H., Komiyama, T., Ophir, E., et al. (2014a). Procedures for behavioral experiments in head-fixed mice. PLoS ONE 9:e88678. doi: 10.1371/journal.pone.0088678

Guo, Z. V., Li, N., Huber, D., Ophir, E., Gutnisky, D., Ting, J. T., et al. (2014b). Flow of cortical activity underlying a tactile decision in mice. Neuron 81, 179-194. doi: 10.1016/j.neuron.2013.10.020

Hafting, T., Fyhn, M., Molden, S., Moser, M. B., and Moser, E. I. (2005). Microstructure of a spatial map in the entorhinal cortex. Nature 436, 801-806. doi: $10.1038 /$ nature 03721

Hahn, J. (1971). Stimulus-response relationships in first-order sensory fibres from cat vibrissae. J. Physiol. 213, 215-226. doi: 10.1113/jphysiol.1971.sp009377

Haidarliu, S., and Ahissar, E. (2001). Size gradients of barreloids in the rat thalamus. J. Compar. Neurol. 429, 372-387.

Halassa, M. M., Siegle, J. H., Ritt, J. T., Ting, J. T., Feng, G., and Moore, C. I. (2011). Selective optical drive of thalamic reticular nucleus generates thalamic bursts and cortical spindles. Nat. Neurosci. 14, 1118-1120. doi: 10.1038/nn.2880

Hanks, T. D., Ditterich, J., and Shadlen, M. N. (2006). Microstimulation of macaque area LIP affects decision-making in a motion discrimination task. Nat. Neurosci. 9, 682-689. doi: 10.1038/nn1683

Harris, J. A., Petersen, R. S., and Diamond, M. E. (1999). Distribution of tactile learning and its neural basis. Proc. Natl. Acad. Sci. U.S.A. 96, 7587-7591. doi: $10.1073 /$ pnas.96.13.7587

Harris, K. D., and Mrsic-Flogel, T. D. (2013). Cortical connectivity and sensory coding. Nature 503, 51-58. doi: 10.1038/nature12654

Harris, R. M. (1986). Morphology of physiologically identified thalamocortical relay neurons in the rat ventrobasal thalamus. J. Compar. Neurol. 251, 491-505. doi: $10.1002 /$ cne.902510405

Harris, R. M. (1987). Axon collaterals in the thalamic reticular nucleus from thalamocortical neurons of the rat ventrobasal thalamus. J. Compar. Neurol. 258, 397-406. doi: 10.1002/cne.902580308

Hartings, J. A., Temereanca, S., and Simons, D. J. (2000). High responsiveness and direction sensitivity of neurons in the rat thalamic reticular nucleus to vibrissa deflections. J. Neurophysiol. 83, 2791-2801. doi: 10.1152/jn.2000.83.5.2791 
Harvey, M. A., Bermejo, R., and Zeigler, H. P. (2001). Discriminative whisking in the head-fixed rat: optoelectronic monitoring during tactile detection and discrimination tasks. Somatosens. Mot. Res. 18, 211-222. doi: 10.1080/01421590120072204

Hassenstein, B., and Reichardt, W. (1956). Systemtheoretische analyse der zeit, reihenfolgen-und vorzeichenauswertung bei der bewegungsperzeption des rüsselkäfers chlorophanus. Z. Naturforsch. 11, 513-524. doi: 10.1515/znb-1956-9-1004

Hattox, A. M., and Nelson, S. B. (2007). Layer V neurons in mouse cortex projecting to different targets have distinct physiological properties. J. Neurophysiol. 98, 3330-3340. doi: 10.1152/jn.00397.2007

Hayama, T., and Ogawa, H. (1997). Regional differences of callosal connections in the granular zones of the primary somatosensory cortex in rats. Brain Res. Bull. 43, 341-347. doi: 10.1016/S0361-9230(97)00018-X

Hayashi, H. (1980). Distributions of vibrissae afferent fiber collaterals in the trigeminal nuclei as revealed by intra-axonal injection of horseradish peroxidase. Brain Res. 183:442. doi: 10.1016/0006-8993(80)90478-3

Helmchen, F., Gilad, A., and Chen, J. L. (2018). Neocortical dynamics during whisker-based sensory discrimination in head-restrained mice. Neuroscience 368, 57-69. doi: 10.1016/j.neuroscience.2017.09.003

Hemelt, M. E., Kwegyir-Afful, E. E., Bruno, R. M., Simons, D. J., and Keller, A. (2010). Consistency of angular tuning in the rat vibrissa system. J. Neurophysiol. 104, 3105-3112. doi: 10.1152/jn.00697.2009

Henderson, T., and Jacquin, M. (1995). What makes subcortical barrels. Cereb. Cortex 11, 123-187. doi: 10.1007/978-1-4757-9616-2_3

Herkenham, M. (1980). Laminar organization of thalamic projections to the rat neocortex. Science 207:532. doi: 10.1126/science.7352263

Herkenham, M. (1986). New perspectives on the organization and evolution of nonspecific thalamocortical projections. Cereb. Cortex 5, 403-445. doi: 10.1007/978-1-4613-2149-1_11

Hernández, A., Zainos, A., and Romo, R. (2000). Neuronal correlates of sensory discrimination in the somatosensory cortex. Proc. Natl. Acad. Sci. U.S.A. 97:6191. doi: 10.1073/pnas.120018597

Hodge, C. Jr., Stevens, R. T., Newman, H., Merola, J., and Chu, C. (1997). Identification of functioning cortex using cortical optical imaging. Neurosurgery 41:1137. doi: 10.1097/00006123-199711000-00023

Hoeflinger, B. F., Bennett-Clarke, C. A., Chiaia, N. L., Killackey, H. P., and Rhoades, R. W. (1995). Patterning of local intracortical projections within the vibrissae representation of rat primary somatosensory cortex. J. Compar. Neurol. 354, 551-563. doi: 10.1002/cne.903540406

Hong, W., Kennedy, A., Burgos-Artizzu, X. P., Zelikowsky, M., Navonne, S. G., Perona, P., et al. (2015). Automated measurement of mouse social behaviors using depth sensing, video tracking, and machine learning. Proc. Natl. Acad. Sci. U.S.A. 112, E5351-E5360. doi: 10.1073/pnas.1515982112

Hoogland, P. V., Welker, E., and Van der Loos, H. (1987). Organization of the projections from barrel cortex to thalamus in mice studied with phaseolus vulgaris-leucoagglutinin and HRP. Exp. Brain Res. 68, 73-87. doi: 10.1007/BF00255235

Hooks, B. M., Hires, S. A., Zhang, Y.-X., Huber, D., Petreanu, L., Svoboda, K., et al. (2011). Laminar analysis of excitatory local circuits in vibrissal motor and sensory cortical areas. PLoS Biol. 9:e1000572. doi: 10.1371/journal.pbio.1000572

Hsiao, S. S., O'shaughnessy, D. M., and Johnson, K. O. (1993). Effects of selective attention on spatial form processing in monkey primary and secondary somatosensory cortex. J. Neurophysiol. 70, 444-447. doi: 10.1152/jn.1993.70.1.444

Hubel, D. H., and Wiesel, T. N. (1974). Sequence regularity and geometry of orientation columns in the monkey striate cortex. J. Compar. Neurol. 158, 267-293. doi: 10.1002/cne.901580304

Huber, D., Petreanu, L., Ghitani, N., Ranade, S., Hromádka, T., Mainen, Z., et al. (2007). Sparse optical microstimulation in barrel cortex drives learned behaviour in freely moving mice. Nature 451, 61-64. doi: 10.1038/nature06445

Huerta, M. F., Frankfurter, A., and Harting, J. K. (1983). Studies of the principal sensory and spinal trigeminal nuclei of the rat: projections to the superior colliculus, inferior olive, and cerebellum. J. Compar. Neurol. 220, 147-167. doi: $10.1002 / \mathrm{cne} .902200204$

Huet, L. A., and Hartmann, M. J. (2014). The search space of the rat during whisking behavior. J. Exp. Biol. 17, 3365-3376. doi: 10.1242/jeb.105338
Hulse, S. H., and Suter, S. (1968). One-drop licking in rats. J. Compar. Physiol. Psychol. 66:536. doi: 10.1037/h0026339

Hutson, K. A., and Masterton, R. B. (1986). The sensory contribution of a single vibrissa's cortical barrel. J. Neurophysiol. 56, 1196-1223. doi: 10.1152/jn.1986.56.4.1196

Iggo, A., and Muir, A. (1969). The structure and function of a slowly adapting touch corpuscle in hairy skin. J. Physiol. 200:763. doi: 10.1113/jphysiol.1969.sp008721

Ito, M. (1985). Processing of vibrissa sensory information within the rat neocortex. J. Neurophysiol. 54, 479-490. doi: 10.1152/jn.1985.54.3.479

Itskov, P. M., Vinnik, E., and Diamond, M. E. (2011). Hippocampal representation of touch-guided behavior in rats: Persistent and independent traces of stimulus and reward location. PLOS ONE 6:e16462. doi: 10.1371/journal.pone.0016462

Iwamura, Y. (1998). Hierarchical somatosensory processing. Curr. Opin. Neurobiol. 8, 522-528. doi: 10.1016/S0959-4388(98)80041-X

Jacob, V., Le Cam, J., Ego-Stengel, V., and Shulz, D. E. (2008). Emergent properties of tactile scenes selectively activate barrel cortex neurons. Neuron 60, 11121125. doi: 10.1016/j.neuron.2008.10.017

Jacquin, M., Golden, J., and Panneton, W. (1988). Structure and function of barrel 'precursor' cells in trigeminal nucleus principalis. Dev. Brain Res. 43, 309-314. doi: 10.1016/0165-3806(88)90109-5

Jacquin, M. F., Barcia, M., and Rhoades, R. W. (1989). Structure-function relationships in rat brainstem subnucleus interpolaris: IV. Projection neurons. J. Compar. Neurol. 282, 45-62. doi: 10.1002/cne.902820105

Jacquin, M. F., Mooney, R. T., and Rhoades, R. W. (1986). Morphology, response properties, and collateral projections of trigeminothalamic neurons in brainstem subnucleus interpolaris of rat. Exp. Brain Res. 61, 457-468. doi: 10.1007/BF00237571

Jacquin, M. F., Renehan, W. E., Rhoades, R. W., and Panneton, W. M. (1993). Morphology and topography of identified primary afferents in trigeminal subnuclei principalis and oralis. J. Neurophysiol. 70, 1911-1936. doi: 10.1152/jn.1993.70.5.1911

Jacquin, M. F., and Rhoadesi, R. W. (1990). Cell structure and response properties in the trigeminal subnucleus oralis. Somatosens. Mot. Res. 7, 265288. doi: $10.3109 / 08990229009144709$

Jenkinson, E. W., and Glickstein, M. (2000). Whiskers, barrels, and cortical efferent pathways in gap crossing by rats. J. Neurophysiol. 84, 1781-1789. doi: 10.1152/jn.2000.84.4.1781

Jensen, K. F., and Killackey, H. P. (1987). Terminal arbors of axons projecting to the somatosensory cortex of the adult rat. I. The normal morphology of specific thalamocortical afferents. J. Neurosci. 7, 3529-3543. doi: 10.1523/JNEUROSCI.07-11-03529.1987

Jiang, W., Tremblay, F., and Chapman, C. (1997). Neuronal encoding of texture changes in the primary and the secondary somatosensory cortical areas of monkeys during passive texture discrimination. J. Neurophysiol. 77, 1656-1662. doi: 10.1152/jn.1997.77.3.1656

Jones, E., and Diamond, I. (1995). The Barrel Cortex of Rodents. New York, NY: Plenum Press.

Jones, E. G. (1975). Some aspects of the organization of the thalamic reticular complex. J. Compar. Neurol. 162, 285-308. doi: 10.1002/cne.901620302

Kandler, S., Mao, D., McNaughton, B. L., and Bonin, V. (2018). Encoding of tactile context in the mouse visual cortex. bioRxiv 199364. doi: 10.1101/199364

Karhu, J., and Tesche, C. (1999). Simultaneous early processing of sensory input in human primary (SI) and secondary (SII) somatosensory cortices. J. Neurophysiol. 81, 2017-2025. doi: 10.1152/jn.1999.81.5.2017

Keehn, J. D., and Arnold, E. M. (1960). Licking rates of albino rats. Science 132, 739-741. doi: 10.1126/science.132.3429.739

Keller, G. B., Bonhoeffer, T., and Hü bener, M. (2012). Sensorimotor mismatch signals in primary visual cortex of the behaving mouse. Neuron $74,809-815$. doi: 10.1016/j.neuron.2012.03.040

Kenan-Vaknin, G., and Teyler, T. J. (1994). Laminar pattern of synaptic activity in rat primary visual cortex: comparison of in vivo and in vitro studies employing the current source density analysis. Brain Res. 635, 37-48. doi: 10.1016/0006-8993(94)91421-4

Kerr, F. W., and Lysak, W. R. (1964). Somatotopic organization of trigeminal-ganglion neurones. Arch. Neurol. 11:593. doi: 10.1001/archneur.1964.00460240025003

Kerr, J. N., de Kock, C. P., Greenberg, D. S., Bruno, R. M., Sakmann, B., and Helmchen, F. (2007). Spatial organization of neuronal population 
responses in layer 2/3 of rat barrel cortex. J. Neurosci. 27, 13316-13328. doi: 10.1523/JNEUROSCI.2210-07.2007

Kiani, R., Hanks, T. D., and Shadlen, M. N. (2008). Bounded integration in parietal cortex underlies decisions even when viewing duration is dictated by the environment. J. Neurosci. 28:3017. doi: 10.1523/JNEUROSCI.4761-07.2008

Kida, H., Shimegi, S., and Sato, H. (2005). Similarity of direction tuning among responses to stimulation of different whiskers in neurons of rat barrel cortex. J. Neurophysiol. 94, 2004-2018. doi: 10.1152/jn.00113.2004

Kim, J., Matney, C. J., Blankenship, A., Hestrin, S., and Brown, S. P. (2014). Layer 6 corticothalamic neurons activate a cortical output layer, layer 5a. J. Neurosci. 34, 9656-9664. doi: 10.1523/JNEUROSCI.1325-14.2014

Kim, U., and Ebner, F. (1999). Barrels and septa: separate circuits in rat barrel field cortex. J. Compar. Neurol. 408, 489-505.

Kleinfeld, D., Ahissar, E., and Diamond, M. E. (2006). Active sensation: insights from the rodent vibrissa sensorimotor system. Curr. Opin. Neurobiol. 16, 435-444. doi: 10.1016/j.conb.2006.06.009

Kleinfeld, D., and Delaney, K. R. (1996). Distributed representation of vibrissa movement in the upper layers of somatosensory cortex revealed with voltagesensitive dyes. J. Compar. Neurol. 375, 89-108.

Kleinfeld, D., Deschênes, M., Wang, F., and Moore, J. D. (2014). More than a rhythm of life: breathing as a binder of orofacial sensation. Nat. Neurosci. 17:647. doi: 10.1038/nn.3693

Kleinfeld, D., Sachdev, R. N., Merchant, L. M., Jarvis, M. R., and Ebner, F. F. (2002). Adaptive filtering of vibrissa input in motor cortex of rat. Neuron 34, 1021-1034. doi: 10.1016/S0896-6273(02)00732-8

Knutsen, P. M., and Ahissar, E. (2009). Orthogonal coding of object location. Trends Neurosci. 32, 101-109. doi: 10.1016/j.tins.2008.10.002

Knutsen, P. M., Derdikman, D., and Ahissar, E. (2005). Tracking whisker and head movements in unrestrained behaving rodents. J. Neurophysiol. 93, 2294-2301. doi: 10.1152/jn.00718.2004

Knutsen, P. M., Pietr, M., and Ahissar, E. (2006). Haptic object localization in the vibrissal system: behavior and performance. J. Neurosci. 26, 8451-8464. doi: 10.1523/JNEUROSCI.1516-06.2006

Kolmac, C. I., Power, B. D., and Mitrofanis, J. (1998). Patterns of connections between zona incerta and brainstem in rats. J. Compar. Neurol. 396, 544-555.

Koralek, K. A., Jensen, K. F., and Killackey, H. P. (1988). Evidence for two complementary patterns of thalamic input to the rat somatosensory cortex. Brain Res. 463, 346-351. doi: 10.1016/0006-8993(88)90408-8

Koralek, K. A., Olavarria, J., and Kellackey, H. P. (1990). Areal and laminar organization of corticocortical projections in the rat somatosensory cortex. J. Compar. Neurol. 299, 133-150. doi: 10.1002/cne.902990202

Kremer, Y., Léger, J.-F., Goodman, D., Brette, R., and Bourdieu, L. (2011). Late emergence of the vibrissa direction selectivity map in the rat barrel cortex. J. Neurosci. 31, 10689-10700. doi: 10.1523/JNEUROSCI.6541-10.2011

Krupa, D. J., Matell, M. S., Brisben, A. J., Oliveira, L. M., and Nicolelis, M. A. (2001). Behavioral properties of the trigeminal somatosensory system in rats performing whisker-dependent tactile discriminations. J. Neurosci. 21, 5752-5763. doi: 10.1523/JNEUROSCI.21-15-05752.2001

Kuhlman, W. N. (1978). Functional topography of the human $\mathrm{mu}$ rhythm. Electroencephalogr. Clin. Neurophysiol. 44, 83-93. doi: 10.1016/0013-4694(78)90107-4

Kwegyir-Afful, E. E. and Keller, A. (2004). Response properties of whisker-related neurons in rat second somatosensory cortex. J. Neurophysiol. 92, 2083-2092. doi: 10.1152/jn.00262.2004

Kwon, S. E., Tsytsarev, V., Erzurumlu, R. S., and O'Connor, D. H. (2018). Organization of orientation-specific whisker deflection responses in layer $2 / 3$ of mouse somatosensory cortex. Neuroscience 368, 46-56. doi: 10.1016/j.neuroscience.2017.07.067

Lam, Y. W., and Sherman, S. S. (2007). Different topography of the reticulothalmic inputs to first-and higher-order somatosensory thalamic relays revealed using photostimulation. J. Neurophysiol. 98, 2903-2909. doi: 10.1152/jn.00782.2007

Land, P. W., Buffer, S. A. Jr., and Yaskosky, J. D. (1995). Barreloids in adult rat thalamus: three-dimensional architecture and relationship to somatosensory cortical barrels. J. Compar. Neurol. 355, 573-588. doi: 10.1002/cne.903550407

Landisman, C. E., Long, M. M., Beierlein, M., Deans, M. R., Paul, D. L., and Connors, B. W. (2002). Electrical synapses in the thalamic reticular nucleus. J. Neurosci. 22, 1002-1009. doi: 10.1523/JNEUROSCI.22-03-01002.2002
Larsen, D. I., Wickersham, I. R., and Callaway, E. M. (2007). Retrograde tracing with recombinant rabies virus reveals correlations between projection targets and dendritic architecture in layer 5 of mouse barrel cortex. Front. Neural Circuits 1:5. doi: 10.3389/neuro.04.005.2007

Larsen, J., and Divac, I. (1978). Selective ablations within the prefrontal cortex of the rat and performance of delayed alternation. Physiol. Psychol. 6, 15-17. doi: 10.3758/BF03326684

Lavallée, P. and Deschênes, M. (2004). Dendroarchitecture and lateral inhibition in thalamic barreloids. J. Neurosci. 24, 6098-6105. doi: 10.1523/JNEUROSCI.0973-04.2004

Lavallée, P., Urbain, N., Dufresne, C., Bokor, H., Acsady, L., and Deschênes, M. (2005). Feedforward inhibitory control of sensory information in higher-order thalamic nuclei. J. Neurosci. 25:7489. doi: 10.1523/JNEUROSCI.2301-05.2005

Lavzin, M., Rapoport, S., Polsky, A., Garion, L., and Schiller, J. (2012). Nonlinear dendritic processing determines angular tuning of barrel cortex neurons in vivo. Nature 490, 397-401. doi: 10.1038/nature11451

Le Cam, J., Estebanez, L., Jacob, V., and Shulz, D. E. (2011). Spatial structure of multiwhisker receptive fields in the barrel cortex is stimulus dependent. J. Neurophysiol. 106, 986-998. doi: 10.1152/jn.00044.2011

Lee, C. C., Diamond, M. E., and Arabzadeh, E. (2016). Sensory prioritization in rats: behavioral performance and neuronal correlates. J. Neurosci. 36, 3243-3253. doi: 10.1523/JNEUROSCI.3636-15.2016

Lee, C. C. Y., Clifford, C. W. G., and Arabzadeh, E. (2019). Temporal cueing enhances neuronal and behavioral discrimination performance in rat whisker system. J. Neurophysiol. 121, 1048-1058. doi: 10.1152/jn.00604.2018

Lee, K. J., and Woolsey, T. A. (1975). A proportional relationship between peripheral innervation density and cortical neuron number in the somatosensory system of the mouse. Brain Res. 99, 349-353. doi: 10.1016/0006-8993(75)90035-9

Lee, S. M., Friedberg, M. H., and Ebner, F. F. (1994). The role of GABAmediated inhibition in the rat ventral posterior medial thalamus. i. Assessment of receptive field changes following thalamic reticular nucleus lesions. $J$ Neurophysiol. 71, 1702-1715. doi: 10.1152/jn.1994.71.5.1702

Lefort, S., Tomm, C., Sarria, J.-C., and Petersen, C. C. (2009). The excitatory neuronal network of the $\mathrm{c} 2$ barrel column in mouse primary somatosensory cortex. Neuron 61, 301-316. doi: 10.1016/j.neuron.2008.12.020

Lewis, L. D., Voigts, J., Flores, F. J., Schmitt, L. I., Wilson, M. A., Halassa, M. M., et al. (2015). Thalamic reticular nucleus induces fast and local modulation of arousal state. eLife 4:e08760. doi: 10.7554/eLife.08760

Li, N., Chen, T.-W., Guo, Z. V., Gerfen, C. R., and Svoboda, K. (2015). A motor cortex circuit for motor planning and movement. Nature 519:51. doi: $10.1038 /$ nature 14178

Lichtenstein, S., Carvell, G. E., and Simons, D. G. (1990). Responses of rat trigeminal ganglion neurons to movements of vibrissae in different directions. Somatosens. Mot. Res. 7, 47-65. doi: 10.3109/08990229009144697

Lin, C., Nicolelis, M., Schneider, J., and Chapin, J. (1990). A major direct GABAergic pathway from zona incerta to neocortex. Science 248:1553. doi: 10.1126/science.2360049

Lu, S.-M., and Lin, R. C. (1993). Thalamic afferents of the rat barrel cortex: a light-and electron-microscopic study using phaseolus vulgaris leucoagglutinin as an anterograde tracer. Somatosens. Mot. Res. 10, 1-16. doi: 10.3109/08990229309028819

Lübke J. H., and Feldmeyer D. (eds.). (2010). The axon of excitatory neurons in the neocortex: projection patterns and target specificity," in New Aspects of Axonal Structure and Function (Boston, MA: Springer). doi: 10.1007/978-1-4419-1676-1_9

Luna, R., Hernández, A., Brody, C. D., and Romo, R. (2005). Neural codes for perceptual discrimination in primary somatosensory cortex. Nat. Neurosci. 8, 1210-1219. doi: 10.1038/nn1513

Ma, P. M. (1991). The barrelettes-architectonic vibrissal representations in the brainstem trigeminal complex of the mouse. normal structural organization. J. Compar. Neurol. 309, 161-199. doi: 10.1002/cne.903090202

Ma, P. M., and Woolsey, T. A. (1984). Cytoarchitectonic correlates of the vibrissae in the medullary trigeminal complex of the mouse. Brain Res. 306:374. doi: 10.1016/0006-8993(84)90390-1

Manns, I. D., Sakmann, B., and Brecht, M. (2004). Sub- and suprathreshold receptive field properties of pyramidal neurons in layers $5 \mathrm{a}$ and 
5b of rat somatosensory barrel cortex. J. Physiol. 556, 601-622. doi: 10.1113/jphysiol.2003.053132

Maravall, M., Petersen, R. S., Fairhall, A. L., Arabzadeh, E., and Diamond, M. E. (2007). Shifts in coding properties and maintenance of information transmission during adaptation in barrel cortex. PLoS Biol. 5:e19. doi: 10.1371/journal.pbio.0050019

Markram, H., Lübke, J., Frotscher, M., Roth, A., and Sakmann, B. (1997). Physiology and anatomy of synaptic connections between thick tufted pyramidal neurones in the developing rat neocortex. J. Physiol. 500, 409-440. doi: 10.1113/jphysiol.1997.sp022031

Matyas, F., Sreenivasan, V., Marbach, F., Wacongne, C., Barsy, B., Mateo, C., et al. (2010). Motor control by sensory cortex. Science 330, 1240-1243. doi: $10.1126 /$ science. 1195797

May, P. J., Sun, W., and Hall, W. C. (1997). Reciprocal connections between the zona incerta and the pretectum and superior colliculus of the cat. Neuroscience 77, 1091-1114. doi: 10.1016/S0306-4522(96)00535-0

Mayrhofer, J. M., Skreb, V., von der Behrens, W., Musall, S., Weber, B., and Haiss, F. (2012). Novel two-alternative forced choice paradigm for bilateral vibrotactile whisker frequency discrimination in head-fixed mice and rats. J. Neurophysiol. 109, 273-284. doi: 10.1152/jn.00488.2012

McDonald, J. S., Adibi, M., Clifford, C. W., and Arabzadeh, E. (2014). Sampling time and performance in rat whisker sensory system. PLoS ONE 9:e116357. doi: 10.1371/journal.pone.0116357

McGuire, L. M., Telian, G., Laboy-Juárez, K. J., Miyashita, T., Lee, D. J., Smith, K. A., et al. (2016). Short time-scale sensory coding in s1 during discrimination of whisker vibrotactile sequences. PLoS Biol. 14:e1002549. doi: 10.1371/journal.pbio.1002549

Mehta, S. B., Whitmer, D., Figueroa, R., Williams, B. A., and Kleinfeld, D. (2007). Active spatial perception in the vibrissa scanning sensorimotor system. PLoS Biol. 5:e15. doi: 10.1371/journal.pbio.0050015

Melaragno, H. P., and Montagna, W. (1953). The tactile hair follicles in the mouse. Anat. Record 115, 129-149. doi: 10.1002/ar.1091150202

Miguelez Fernández, A. M. M., Burman, A., Martínez Cáceres, A. I., Mininni, C. J., Zanutto, B. S., and Lew, S. E. (2018a). A spherical treadmill system to train head-fixed adult rats. J. Neurosci. Methods 297, 22-30. doi: 10.1016/j.jneumeth.2017.12.018

Mima, T., Nagamine, T., Nakamura, K., and Shibasaki, H. (1998). Attention modulates both primary and second somatosensory cortical activities in humans: a magnetoencephalographic study. J. Neurophysiol. 80, 2215-2221. doi: 10.1152/jn.1998.80.4.2215

Minnery, B. S., Bruno, R. M., and Simons, D. J. (2003). Response transformation and receptive-field synthesis in the lemniscal trigeminothalamic circuit. $J$. Neurophysiol. 90, 1556-1570. doi: 10.1152/jn.00111.2003

Minnery, B. S., and Simons, D. J. (2003). Response properties of whisker-associated trigeminothalamic neurons in rat nucleus principalis. J. Neurophysiol. 89, 40-56. doi: 10.1152/jn.00272.2002

Mitchinson, B., Grant, R. A., Arkley, K., Rankov, V., Perkon, I., and Prescott, T. J. (2011). Active vibrissal sensing in rodents and marsupials. Philos. Trans. R. Soc. B Biol. Sci. 366, 3037-3048. doi: 10.1098/rstb.2011.0156

Mitchinson, B., Martin, C. J., Grant, R. A., and Prescott, T. J. (2007). Feedback control in active sensing: rat exploratory whisking is modulated by environmental contact. Proc. R. Soc. B Biol. Sci. 274, 1035-1041. doi: 10.1098/rspb.2006.0347

Mitrofanis, J. (2005). Some certainty for the "zone of uncertainty"? Exploring the function of the zona incerta. Neuroscience 130, 1-15. doi: 10.1016/j.neuroscience.2004.08.017

Mitrofanis, J., and Mikuletic, L. (1999). Organisation of the cortical projection to the zona incerta of the thalamus. J. Compar. Neurol. 412, 173-185.

Moore, C. I., and Nelson, S. B. (1998). Spatio-temporal subthreshold receptive fields in the vibrissa representation of rat primary somatosensory cortex. J. Neurophysiol. 80, 2882-2892. doi: 10.1152/jn.1998.80. 6.2882

Moore, J. D., Deschênes, M., Furuta, T., Huber, D., Smear, M. C., Demers, M., et al. (2013). Hierarchy of orofacial rhythms revealed through whisking and breathing. Nature 497:205. doi: 10.1038/nature12076

Moore, J. D., Deschênes, M., Kurnikova, A., and Kleinfeld, D. (2014). Activation and measurement of free whisking in the lightly anesthetized rodent. Nat. Protoc. 9:1792. doi: 10.1038/nprot.2014.119
Morita, T., Kang, H., Wolfe, J., Jadhav, S. P., and Feldman, D. E. (2011) Psychometric curve and behavioral strategies for whisker-based texture discrimination in rats. PLoS ONE 6:e20437. doi: 10.1371/journal.pone.0020437 Mountcastle, V., LaMotte, R. B., and Carli, G. H. (1972). Detection thresholds for stimuli in humans and monkeys: comparison with threshold events in mechanoreceptive afferent nerve fibers innervating the monkey hand. $J$. Neurophysiol. 35, 122-136. doi: 10.1152/jn.1972.35.1.122

Munger, B. L., Pubols, L. M., and Pubols, B. H. (1971). The merkel rete papilla-a slowly adapting sensory receptor in mammalian glabrous skin. Brain Res. 29, 47-61. doi: 10.1016/0006-8993(71)90416-1

Musall, S., Von Der Behrens, W., Mayrhofer, J. M., Weber, B., Helmchen, F., and Haiss, F. (2014). Tactile frequency discrimination is enhanced by circumventing neocortical adaptation. Nat. Neurosci. 17:1567. doi: 10.1038/nn.3821

Narayanan, R. T., Udvary, D., and Oberlaender, M. (2017). Cell type-specific structural organization of the six layers in rat barrel cortex. Front. Neuroanat. 11:91. doi: 10.3389/fnana.2017.00091

Newsome, W. T., Britten, K. H., and Movshon, J. A. (1989). Neuronal correlates of a perceptual decision. Nature 341, 52-54. doi: 10.1038/341052a0

Nicolelis, M., Chapin, J., and Lin, R. (1992). Somatotopic maps within the zona incerta relay parallel GABAergic somatosensory pathways to the neocortex, superior colliculus, and brainstem. Brain Res. 577, 134-141. doi: 10.1016/0006-8993(92)90546-L

Niell, C. M., and Stryker, M. P. (2010). Modulation of visual responses by behavioral state in mouse visual cortex. Neuron 65, 472-479. doi: 10.1016/j.neuron.2010.01.033

Nikbakht, N., Tafreshiha, A., Zoccolan, D., and Diamond, M. E. (2018). Supralinear and supramodal integration of visual and tactile signals in rats: psychophysics and neuronal mechanisms. Neuron 97, 626-639. doi: 10.1016/j.neuron.2018.01.003

Nord, S. (1967). Somatotopic organization in the spinal trigeminal nucleus, the dorsal column nuclei and related structures in the rat. J. Compar. Neurol. 130 343-356. doi: 10.1002/cne.901300406

Oberlaender, M., de Kock, C., Bruno, R., Ramirez, A., Meyer, H. S., Dercksen, V. J., et al. (2012). Cell type specific three-dimensional structure of thalamocortical circuits in a column of rat vibrissal cortex. Cereb. Cortex 22, 2375-2391. doi: $10.1093 /$ cercor/bhr317

O'Connor, D. H., Clack, N. G., Huber, D., Komiyama, T., Myers, E. W., and Svoboda, K. (2010). Vibrissa-based object localization in head-fixed mice. J. Neurosci. 30:1947. doi: 10.1523/JNEUROSCI.3762-09.2010

O'Connor, S. M., Berg, R. W., and Kleinfeld, D. (2002). Coherent electrical activity between vibrissa sensory areas of cerebellum and neocortex is enhanced during free whisking. J. Neurophysiol. 87, 2137-2148. doi: 10.1152/jn.00229.2001

Ohki, K., Chung, S., Ch'ng, Y. H., Kara, P., and Reid, R. C. (2005). Functional imaging with cellular resolution reveals precise micro-architecture in visual cortex. Nature 433, 597-603. doi: 10.1038/nature03274

Ohki, K., Chung, S., Kara, P., Hübener, M., Bonhoeffer, T., and Reid, R. C. (2006). Highly ordered arrangement of single neurons in orientation pinwheels. Nature 442, 925-928. doi: 10.1038/nature05019

O'Keefe, J. (1976). Place units in the hippocampus of the freely moving rat. Exp. Neurol. 51, 78-109. doi: 10.1016/0014-4886(76)90055-8

O'keefe, J., and Conway, D. H. (1978). Hippocampal place units in the freely moving rat: why they fire where they fire. Exp. Brain Res. 31, 573-590. doi: 10.1007/BF00239813

O'keefe, J., and Nadel, L. (1978). The Hippocampus as a Cognitive Map. Oxford: Oxford University Press.

Ollerenshaw, D. R., Bari, B. A., Millard, D. C., Orr, L. E., Wang, Q., and Stanley, G. B. (2012). Detection of tactile inputs in the rat vibrissa pathway. J. Neurophysiol. 108, 479-490. doi: 10.1152/jn.00004.2012

Oram, M. (2011). Visual stimulation decorrelates neuronal activity. $J$. Neurophysiol. 105, 942-957. doi: 10.1152/jn.00711.2009

Osborne, L. C., Bialek, W., and Lisberger, S. G. (2004). Time course of information about motion direction in visual area MT of macaque monkeys. J. Neurosci. 24, 3210-3222. doi: 10.1523/JNEUROSCI.5305-03.2004

Otazu, G. H., Tai, L. H., Yang, Y., and Zador, A. M. (2009). Engaging in an auditory task suppresses responses in auditory cortex. Nat. Neurosci. 12, 646-654. doi: $10.1038 / \mathrm{nn} .2306$

Petersen, C. C. (2007). The functional organization of the barrel cortex. Neuron 56 339-355. doi: 10.1016/j.neuron.2007.09.017 
Petersen, C. C., and Crochet, S. (2013). Synaptic computation and sensory processing in neocortical layer 2/3. Neuron 78, 28-48. doi: 10.1016/j.neuron.2013.03.020

Petersen, R. S., and Diamond, M. E. (2000). Spatial-temporal distribution of whisker-evoked activity in rat somatosensory cortex and the coding of stimulus location. J. Neurosci. 20, 6135-6143. doi: 10.1523/JNEUROSCI.20-16-06135.2000

Pierret, T., Lavallée, P., and Deschênes, M. (2000). Parallel streams for the relay of vibrissal information through thalamic barreloids. J. Neurosci. 20, 7455-7462. doi: 10.1523/JNEUROSCI.20-19-07455.2000

Pinault, D. (2004). The thalamic reticular nucleus: structure, function and concept. Brain Res. Rev. 46, 1-31. doi: 10.1016/j.brainresrev.2004.04.008

Pinault, D., Bourassa, J., and Deschênes, M. (1995). The axonal arborization of single thalamic reticular neurons in the somatosensory thalamus of the rat. Eur. J. Neurosci. 7, 31-40. doi: 10.1111/j.1460-9568.1995.tb01017.x

Pinto, D. J., Brumberg, J. C., and Simons, D. J. (2000). Circuit dynamics and coding strategies in rodent somatosensory cortex. J. Neurophysiol. 83:1158. doi: $10.1152 /$ jn.2000.83.3.1158

Polley, D. B., Rickert, J. L., and Frostig, R. D. (2005). Whisker-based discrimination of object orientation determined with a rapid training paradigm. Neurobiol. Learn. Mem. 83, 134-142. doi: 10.1016/j.nlm.2004.10.005

Poulet, J. F., Fernandez, L. M., Crochet, S., and Petersen, C. C. (2012). Thalamic control of cortical states. Nat. Neurosci. 15, 370-372. doi: 10.1038/ nn.3035

Poulet, J. F., and Petersen, C. C. (2008). Internal brain state regulates membrane potential synchrony in barrel cortex of behaving mice. Nature 454, 881-885. doi: 10.1038/nature07150

Power, B. D., Kolmac, C. I., and Mitrofanis, J. (1999). Evidence for a large projection from the zona incerta to the dorsal thalamus. J. Compar. Neurol. 404, 554-565.

Prigg, T., Goldreich, D., Carvell, G. E., and Simons, D. J. (2002). Texture discrimination and unit recordings in the rat whisker/barrel system. Physiol. Behav. 77, 671-675. doi: 10.1016/S0031-9384(02)00917-4

Pubols, B. H., Donovick, P. J., and Pubols, L. M. (1973). Opossum trigeminal afferents associated with vibrissa and rhinarial mechanoreceptors. Brain Behav. Evol. 7, 360-381. doi: 10.1159/000124423

Puccini, G. D., Compte, A., and Maravall, M. (2006). Stimulus dependence of barrel cortex directional selectivity. PLoS ONE 1:e137. doi: 10.1371/journal.pone.0000137

Ragozzino, M. E., Adams, S., and Kesner, R. P. (1998). Differential involvement of the dorsal anterior cingulate and prelimbic-infralimbic areas of the rodent prefrontal cortex in spatial working memory. Behav. Neurosci. 112:293. doi: 10.1037//0735-7044.112.2.293

Ramaswamy, S., and Markram, H. (2015). Anatomy and physiology of the thick-tufted layer 5 pyramidal neuron. Front. Cell. Neurosci. 9:233. doi: 10.3389/fncel.2015.00233

Reichardt, W. (1961). "Autocorrelation, a principle for the evaluation of sensory information by the central nervous system," in Sensory Communication, Chapter 17, ed W. Rosenblith (Cambridge: MIT Press), 303-317.

Renehan, W. E., and Munger, B. L. (1986). Degeneration and regeneration of peripheral nerve in the rat trigeminal system. I. Identification and characterization of the multiple afferent innervation of the mystacial vibrissae. J. Compar. Neurol. 246, 129-145. doi: 10.1002/cne.902460109

Ress, D., and Heeger, D. (2003). Neuronal correlates of perception in early visual cortex. Nat. Neurosci. 6:414. doi: 10.1038/nn1024

Reyes, A., and Sakmann, B. (1999). Developmental switch in the shortterm modification of unitary epsps evoked in layer $2 / 3$ and layer 5 pyramidal neurons of rat neocortex. J. Neurosci. 19, 3827-3835. doi: 10.1523/JNEUROSCI.19-10-03827.1999

Rice, F. L., Fundin, B. T., Arvidsson, J., Aldskogius, H., and Johansson, O. (1997). Comprehensive immunofluorescence and lectin binding analysis of vibrissal follicle sinus complex innervation in the mystacial pad of the rat. J. Compar. Neurol. 385, 149-184.

Rice, F. L., Mance, A., and Munger, B. L. (1986). A comparative light microscopic analysis of the sensory innervation of the mystacial pad. i. innervation of vibrissal follicle-sinus complexes. J. Compar. Neurol. 252, 154174. doi: 10.1002/cne.902520203
Rigosa, J., Lucantonio, A., Noselli, G., Fassihi, A., Zorzin, E., Manzino, F., et al. (2017). Dye-enhanced visualization of rat whiskers for behavioral studies. Elife 6:e25290. doi: 10.7554/eLife.25290

Romo, R., Hernández, A., and Zainos, A. (2004). Neuronal correlates of a perceptual decision in ventral premotor cortex. Neuron 41, 165-173. doi: 10.1016/S0896-6273(03)00817-1

Romo, R., Hernández, A., Zainos, A., Brody, C. D., and Lemus, L. (2000). Sensing without touching psychophysical performance based on cortical microstimulation. Neuron 26, 273-278. doi: 10.1016/S0896-6273(00)81156-3

Romo, R., Hernández, A., Zainos, A., Lemus, L., and Brody, C. D. (2002). Neuronal correlates of decision-making in secondary somatosensory cortex. Nat. Neurosci. 5, 1217-1225. doi: 10.1038/nn950

Romo, R., Hernández, A., Zainos, A., and Salinas, E. (1998). Somatosensory discrimination based on cortical microstimulation. Nature 392, 387-390. doi: $10.1038 / 32891$

Rougeul, A., Bouyer, J. J., Dedet, L., and Debray, O. (1979). Fast somatoparietal rhythms during combined focal attention and immobility in baboon and squirrel monkey. Electroencephalogr. Clin. Neurophysiol. 46, 310-319. doi: 10.1016/0013-4694(79)90205-0

Sabri, M. M., Adibi, M., and Arabzadeh, E. (2016). Dynamics of population activity in rat sensory cortex: network correlations predict anatomical arrangement and information content. Front. Neural Circuits 10:49. doi: 10.3389/fncir.2016.00049

Sachdev, R., Jenkinson, E., Zeigler, H., and Ebner, F. (2001). "Sensorimotor plasticity in the rodent vibrissa system," in The Mutable Brain: Dynamic and Plastic Features of the Developing and Mature Brain, Chapter 4, ed J. Kaas (Amsterdam: Harwood Academic Publishers), 140-188.

Salinas, E., Hernandez, A., Zainos, A., and Romo, R. (2000). Periodicity and firing rate as candidate neural codes for the frequency of vibrotactile stimuli. J. Neurosci. 20, 5503-5515. doi: 10.1523/JNEUROSCI.20-14-05503.2000

Sánchez-Santed, F., de Bruin, J. P., Heinsbroek, R. P., and Verwer, R. W. (1997). Spatial delayed alternation of rats in a t-maze: effects of neurotoxic lesions of the medial prefrontal cortex and of T-maze rotations. Behav. Brain Res. 84, 73-79. doi: 10.1016/S0166-4328(97)83327-X

Saporta, S., and Kruger, L. (1977). The organization of thalamocortical relay neurons in the rat ventrobasal complex studied by the retrograde transport of horseradish peroxidase. J. Compar. Neurol. 174, 187-208. doi: 10.1002/cne.901740202

Schaeffer, R. W., and Premack, D. (1961). Licking rates in infant albino rats. Science 134, 1980-1981. doi: 10.1126/science.134.3494.1980

Scheibel, M. E., and Scheibel, A. B. (1966). The organization of the nucleus reticularis thalami: a golgi study. Brain Res. 1, 43-62. doi: 10.1016/0006-8993(66)90104-1

Schubert, D., Kötter, R., Luhmann, H., and Staiger, J. (2006). Morphology, electrophysiology and functional input connectivity of pyramidal neurons characterizes a genuine layer Va in the primary somatosensory cortex. Cereb. Cortex 16, 223-236. doi: 10.1093/cercor/bhi100

Schubert, D., Staiger, J. F., Cho, N., Kötter, R., Zilles, K., and Luhmann, H. J. (2001). Layer-specific intracolumnar and transcolumnar functional connectivity of layer V pyramidal cells in rat barrel cortex. J. Neurosci. 21:3580. doi: 10.1523/JNEUROSCI.21-10-03580.2001

Schwarz, C., Hentschke, H., Butovas, S., Haiss, F., Stüttgen, M. C., Gerdjikov, T. V., et al. (2010). The head-fixed behaving rat - procedures and pitfalls. Somatosens. Mot. Res. 27, 131-148. doi: 10.3109/08990220.2010.513111

Shadlen, M. N., Britten, K. H., Newsome, W. T., and Movshon, J. A. (1996). A computational analysis of the relationship between neuronal and behavioral responses to visual motion. J. Neurosci. 16:1486. doi: 10.1523/JNEUROSCI.16-04-01486.1996

Shaw, V., and Mitrofanis, J. (2002). Anatomical evidence for somatotopic maps in the zona incerta of rats. Anat. Embryol. 206, 119-130. doi: 10.1007/s00429-002-0280-7

Shimegi, S., Akasaki, T., Ichikawa, T., and Sato, H. (2000). Physiological and anatomical organization of multiwhisker response interactions in the barrel cortex of rats. J. Neurosci. 20, 6241-6248. doi: 10.1523/JNEUROSCI.20-16-06241.2000

Shimegi, S., Ichikawa, T., Akasaki, T., and Sato, H. (1999). Temporal characteristics of response integration evoked by multiple whisker 
stimulations in the barrel cortex of rats. J. Neurosci. 19, 10164-10175. doi: 10.1523/JNEUROSCI.19-22-10164.1999

Shipley, M. (1974). Response characteristics of single units in the rat's trigeminal nuclei to vibrissa displacements. J. Neurophysiol. 37, 73-90. doi: 10.1152/jn.1974.37.1.73

Shosaku, A. (1985). A comparison of receptive field properties of vibrissa neurons between the rat thalamic reticular and ventro-basal nuclei. Brain Res. 347, 36-40. doi: 10.1016/0006-8993(85)90886-8

Silverman, J. d., and Kruger, L. (1985). Projections of the rat trigeminal sensory nuclear complex demonstrated by multiple fluorescent dye retrograde transport. Brain Res. 361, 383-388. doi: 10.1016/0006-8993(85)91308-3

Simons, D. J. (1978). Response properties of vibrissa units in rat SI somatosensory neocortex. J. Neurophysiol. 41, 798-820. doi: 10.1152/jn.1978.41.3.798

Simons, D. J., and Carvell, G. E. (1989). Thalamocortical response transformation in the rat vibrissa/barrel system. J. Neurophysiol. 61:311. doi: 10.1152/jn.1989.61.2.311

Simpson, K., Wang, Y., and Lin, R. C. (2008). Patterns of convergence in rat zona incerta from the trigeminal nuclear complex: light and electron microscopic study. J. Compar. Neurol. 507, 1521-1541. doi: 10.1002/cne.21624

Skinner, J., and Yingling, C. (1977). Central gating mechanisms that regulate event-related potentials and behavior. Prog. Clin. Neurophysiol. 1, 30-69.

Sofroniew, N. J., Cohen, J. D., Lee, A. K., and Svoboda, K. (2014). Natural whiskerguided behavior by head-fixed mice in tactile virtual reality. J. Neurosci. 34, 9537-9550. doi: 10.1523/JNEUROSCI.0712-14.2014

Sreenivasan, V., Kyriakatos, A., Mateo, C., Jaeger, D., and Petersen, C. C. (2016). Parallel pathways from whisker and visual sensory cortices to distinct frontal regions of mouse neocortex. Neurophotonics 4:031203. doi: 10.1117/1.NPh.4.3.031203

Steriade, M., Deschênes, M., Domich, L., and Mulle, C. (1985). Abolition of spindle oscillations in thalamic neurons disconnected from nucleus reticularis thalami. J. Neurophysiol. 54, 1473-1497. doi: 10.1152/jn.1985.54.6.1473

Steriade, M., Domich, L., and Oakson, G. (1986). Reticularis thalami neurons revisited: activity changes during shifts in states of vigilance. J. Neurosci. 6, 68-81. doi: 10.1523/JNEUROSCI.06-01-00068.1986

Steriade, M., McCormick, D. A., and Sejnowski, T. J. (1993). Thalamocortical oscillations in the sleeping and aroused brain. Science 262, 679-685. doi: $10.1126 /$ science. 8235588

Stüttgen, M. C, and Schwarz, C. (2008). Psychophysical and neurometric detection performance under stimulus uncertainty. Nat. Neurosci. 11, 1091-1099. doi: $10.1038 / \mathrm{nn} .2162$

Stüttgen, M. C., and Schwarz, C. (2010). Integration of vibrotactile signals for whisker-related perception in rats is governed by short time constants: comparison of neurometric and psychometric detection performance. J. Neurosci. 30, 2060-2069. doi: 10.1523/JNEUROSCI.3943-09.2010

Sullivan, J., Mitchinson, B., Pearson, M., Evans, M., Lepora, N., Fox, C., et al. (2012). Tactile discrimination using active whisker sensors. Sens. J. IEEE 12, 350-362. doi: 10.1109/JSEN.2011.2148114

Sumser, A., Mease, R. A., Sakmann, B., and Groh, A. (2017). Organization and somatotopy of corticothalamic projections from $15 \mathrm{~b}$ in mouse barrel cortex. Proc. Natl. Acad. Sci. U.S.A. 114, 8853-8858. doi: 10.1073/pnas.1704302114

Szwed, M., Bagdasarian, K., and Ahissar, E. (2003). Encoding of vibrissal active touch. Neuron 40, 621-630. doi: 10.1016/S0896-6273(03)00671-8

Szwed, M., Bagdasarian, K., Blumenfeld, B., Barak, O., Derdikman, D., and Ahissar, E. (2006). Responses of trigeminal ganglion neurons to the radial distance of contact during active vibrissal touch. J. Neurophysiol. 95, 791-802. doi: 10.1152/jn.00571.2005

Talbot, W. H., Darian-Smith, I., Kornhuber, H. H., and Mountcastle, V. B. (1968). The sense of flutter-vibration: comparison of the human capacity with response patterns of mechanoreceptive afferents from the monkey hand. J. Neurophysiol. 31:301. doi: 10.1152/jn.1968.31.2.301

Taube, J. S. (1998). Head direction cells and the neurophysiological basis for a sense of direction. Prog. Neurobiol. 55, 225-256. doi: 10.1016/S0301-0082(98)00004-5

Terenzi, M. G., Zagon, A., and Roberts, M. H. (1995). Efferent connections from the anterior pretectal nucleus to the diencephalon and mesencephalon in the rat. Brain Res. 701, 183-191. doi: 10.1016/0006-8993(95)01001-8

Thomas, G. J., and Brito, G. N. (1980). Recovery of delayed alternation in rats after lesions in medial frontal cortex and septum. J. Compar. Physiol. Psychol. 94:808. doi: $10.1037 /$ h0077834
Thomson, A. M., and Bannister, A. P. (2003). Interlaminar connections in the neocortex. Cereb. Cortex 13, 5-14. doi: 10.1093/cercor/13.1.5

Timofeeva, E., Mérette, C., Emond, C., Lavallée, P., and Deschênes, M. (2003). A map of angular tuning preference in thalamic barreloids. J. Neurosci. 23, 10717-10723. doi: 10.1523/JNEUROSCI.23-33-10717.2003

Topchiy, I. A., Wood, R. M., Peterson, B., Navas, J. A., Rojas, M. J., and Rector, D. M. (2009). Conditioned lick behavior and evoked responses using whisker twitches in head restrained rats. Behav. Brain Res. 197, 16-23. doi: 10.1016/j.bbr.2008.07.032

Towal, R. B., and Hartmann, M. J. (2006). Right-left asymmetries in the whisking behavior of rats anticipate head movements. J. Neurosci. 26, 8838-8846. doi: 10.1523/JNEUROSCI.0581-06.2006

Towal, R. B., and Hartmann, M. J. (2008). Variability in velocity profiles during free-air whisking behavior of unrestrained rats. J. Neurophysiol. 100, 740-752. doi: 10.1152/jn.01295.2007

Trageser, J. C., and Keller, A. (2004). Reducing the uncertainty: gating of peripheral inputs by zona incerta. J. Neurosci. 24, 8911-8915. doi: 10.1523/JNEUROSCI.3218-04.2004

Uka, T., and DeAngelis, G. (2003). Contribution of middle temporal area to coarse depth discrimination: comparison of neuronal and psychophysical sensitivity. J. Neurosci. 23, 3515-3530. doi: 10.1523/JNEUROSCI.23-08-03515.2003

Urbain, N., and Deschênes, M. (2007). Motor cortex gates vibrissal responses in a thalamocortical projection pathway. Neuron 56, 714-725. doi: $10.1016 /$ j.neuron.2007.10.023

Urbain, N., and Deschênes, M. (2007). A new thalamic pathway of vibrissal information modulated by the motor cortex. J. Neurosci. 27, 12407-12412. doi: 10.1523/JNEUROSCI.2914-07.2007

van der Loos, H. (1976). Barreloids in mouse somatosensory thalamus. Neurosci. Lett. 2, 1-6. doi: 10.1016/0304-3940(76)90036-7

Van Ham, J. J., and Yeo, C. H. (1992). Somatosensory trigeminal projections to the inferior olive, cerebellum and other precerebellar nuclei in rabbits. Eur. J. Neurosci. 4, 302-317. doi: 10.1111/j.1460-9568.1992.tb00878.x

Varga, C., Sík, A., Lavallée, P., and Deschênes, M. (2002). Dendroarchitecture of relay cells in thalamic barreloids: a substrate for cross-whisker modulation. J. Neurosci. 22, 6186-6194. doi: 10.1523/JNEUROSCI.22-14-06186.2002

Veinante, P., and Deschênes, M. (1999). Single-and multi-whisker channels in the ascending projections from the principal trigeminal nucleus in the rat. $J$. Neurosci. 19:5085. doi: 10.1523/JNEUROSCI.19-12-05085.1999

Veinante, P., Jacquin, M. F., and Deschênes, M. (2000). Thalamic projections from the whisker-sensitive regions of the spinal trigeminal complex in the rat. $J$. Compar. Neurol. 420, 233-243.

Verma, A., and Moghaddam, B. (1996). NMDA receptor antagonists impair prefrontal cortex function as assessed via spatial delayed alternation performance in rats: modulation by dopamine. J. Neurosci. 16, 373-379. doi: 10.1523/JNEUROSCI.16-01-00373.1996

Vincent, S. B. (1912). The Functions of the Vibrissae in the Behavior of the White Rat. Chicago, IL: University of Chicago.

Vincent, S. B. (1913). The tactile hair of the white rat. J. Compar. Neurol. 23, 1-34. doi: 10.1002/cne.900230101

von Heimendahl, M., Itskov, P. M., Arabzadeh, E., and Diamond, M. E. (2007). Neuronal activity in rat barrel cortex underlying texture discrimination. PLoS Biol. 5:e305. doi: 10.1371/journal.pbio.0050305

Waite, P. M., and Cragg, B. G. (1982). The peripheral and central changes resulting from cutting or crushing the afferent nerve supply to the whiskers. Proc. R. Soc. Lond. Ser. B Biol. Sci. 214, 191-211. doi: 10.1098/rspb.1982.0004

Welker, C. (1971). Microelectrode delineation of fine grain somatotopic organization of (SMI) cerebral neocortex in albino rat. Brain Res. 26, 259-275. doi: 10.1016/S0006-8993(71)80004-5

Welker, C., and Woolsey, T. A. (1974). Structure of layer IV in the somatosensory neocortex of the rat: description and comparison with the mouse. J. Compar. Neurol. 158, 437-453. doi: 10.1002/cne.901580405

Welker, E., Hoogland, P. V., and Van der Loos, H. (1988). Organization of feedback and feedforward projections of the barrel cortex: a PHA-l study in the mouse. Exp. Brain Res. 73, 411-435. doi: 10.1007/BF00248234

Welker, W. (1964). Analysis of sniffing of the albino rat. Behaviour 22, 223-244. doi: 10.1163/156853964X00030

White, E. L., and Czeiger, D. (1991). Synapses made by axons of callosal projection neurons in mouse somatosensory cortex: emphasis on intrinsic 
connections. J. Compar. Neurol. 303, 233-244. doi: 10.1002/cne.9030 30206

White, E. L., and DeAmicis, R. A. (1977). Afferent and efferent projections of the region in mouse sml cortex which contains the posteromedial barrel subfield. J. Compar. Neurol. 175, 455-481. doi: 10.1002/cne.9017 50405

Wilent, W. B., and Contreras, D. (2004). Synaptic responses to whisker deflections in rat barrel cortex as a function of cortical layer and stimulus intensity. J. Neurosci. 24, 3985-3998. doi: 10.1523/JNEUROSCI.578203.2004

Wilent, W. B., and Contreras, D. (2005). Dynamics of excitation and inhibition underlying stimulus selectivity in rat somatosensory cortex. Nat. Neurosci. 8, 1364-1370. doi: 10.1038/nn1545

Williams, M. N., Zahm, D. S., and Jacquin, M. F. (1994). Differential foci and synaptic organization of the principal and spinal trigeminal projections to the thalamus in the rat. Eur. J. Neurosci. 6, 429-453. doi: $10.1111 /$ j.1460-9568.1994.tb00286.x

Wineski, L. (1983). Movements of the cranial vibrissae in the golden hamster (Mesocricetus auratus). J. Zool. 200, 261-280. doi: 10.1111/j.1469-7998.1983.tb05788.x

Wineski, L. (1985). Facial morphology and vibrissal movement in the golden hamster. J. Morphol. 183, 199-217. doi: 10.1002/jmor.1051830208

Wolf, C., Waksman, D., Finger, S., and Almli, C. R. (1987). Large and small medial frontal cortex lesions and spatial performance of the rat. Brain Res. Bull. 18, 1-5. doi: 10.1016/0361-9230(87)90025-6

Woolsey, T. A., and van der Loos, H. (1970). The structural organization of layer IV in the somatosensory region (SI) of mouse cerebral cortex. The description of a cortical field composed of discrete cytoarchitectonic units. Brain Res. 17, 205-242. doi: 10.1016/0006-8993(70)90079-X

Woolston, D. C., La Londe, J. R., and Gibson, J. M. (1982). Comparison of response properties of cerebellar- and thalamic-projecting interpolaris neurons. J. Neurophysiol. 48, 160-173. doi: 10.1152/jn.1982.48.1.160
Yamashita, T., Vavladeli, A., Pala, A., Galan, K., Crochet, S., Petersen, S., et al. (2018). Diverse long-range axonal projections of excitatory layer $2 / 3$ neurons in mouse barrel cortex. Front. Neuroanat. 12:33. doi: 10.3389/fnana.2018.00033

Yang, Y., and Zador, A. M. (2012). Differences in sensitivity to neural timing among cortical areas. J. Neurosci. 32, 15142-15147. doi: 10.1523/JNEUROSCI.1411-12.2012

Yu, C., Derdikman, D., Haidarliu, S., and Ahissar, E. (2006). Parallel thalamic pathways for whisking and touch signals in the rat. PLoS Biol. 4:e124. doi: 10.1371/journal.pbio.0040124

Zucker, E., and Welker, W. (1969). Coding of somatic sensory input by vibrissae neurons in the rat's trigeminal ganglion. Brain Res. 12:138. doi: 10.1016/0006-8993(69)90061-4

Zuo, Y., and Diamond, M. E. (2019a). Rats generate vibrissal sensory evidence until boundary crossing triggers a decision. Curr. Biol. 29, 1415-1424. doi: 10.1016/j.cub.2019.03.016

Zuo, Y., and Diamond, M. E. (2019b). Texture identification by bounded integration of sensory cortical signals. Curr. Biol. 29, 1425-1435. doi: 10.1016/j.cub.2019.03.017

Zuo, Y., Perkon, I., and Diamond, M. (2011). Whisking and whisker kinematics during a texture classification task. Philos. Trans. R. Soc. B Biol. Sci. 366, 3058-3069. doi: 10.1098/rstb.2011.0161

Conflict of Interest Statement: The author declares that the research was conducted in the absence of any commercial or financial relationships that could be construed as a potential conflict of interest.

Copyright (c) 2019 Adibi. This is an open-access article distributed under the terms of the Creative Commons Attribution License (CC BY). The use, distribution or reproduction in other forums is permitted, provided the original author(s) and the copyright owner(s) are credited and that the original publication in this journal is cited, in accordance with accepted academic practice. No use, distribution or reproduction is permitted which does not comply with these terms. 